\title{
Measurements of methane emissions from natural gas gathering facilities and processing plants: measurement methods
}

\author{
J. R. Roscioli ${ }^{1}$, T. I. Yacovitch ${ }^{1}$, C. Floerchinger ${ }^{1}$, A. L. Mitchell ${ }^{2}$, D. S. Tkacik ${ }^{2}$, R. Subramanian ${ }^{2}$, D. M. Martinez ${ }^{3}$, \\ T. L. Vaughn ${ }^{3}$, L. Williams ${ }^{5}$, D. Zimmerle ${ }^{4}$, A. L. Robinson ${ }^{2}$, S. C. Herndon ${ }^{1}$, and A. J. Marchese ${ }^{3}$ \\ ${ }^{1}$ Aerodyne Research Inc., Billerica, MA, USA \\ ${ }^{2}$ Department of Mechanical Engineering, Carnegie Mellon University, Pittsburgh, PA 15213, USA \\ ${ }^{3}$ Department of Mechanical Engineering, Colorado State University, Fort Collins, CO 80523, USA \\ ${ }^{4}$ The Energy Institute, Colorado State University, Fort Collins, CO 80523, USA \\ ${ }^{5}$ Fort Lewis College, Durango, CO 81301, USA
}

Correspondence to: S. C. Herndon (herndon@aerodyne.com)

Received: 29 October 2014 - Published in Atmos. Meas. Tech. Discuss.: 11 December 2014

Revised: 31 March 2015 - Accepted: 10 April 2015 - Published: 7 May 2015

\begin{abstract}
Increased natural gas production in recent years has spurred intense interest in methane $\left(\mathrm{CH}_{4}\right)$ emissions associated with its production, gathering, processing, transmission, and distribution. Gathering and processing facilities (G\&P facilities) are unique in that the wide range of gas sources (shale, coal-bed, tight gas, conventional, etc.) results in a wide range of gas compositions, which in turn requires an array of technologies to prepare the gas for pipeline transmission and distribution. We present an overview and detailed description of the measurement method and analysis approach used during a 20-week field campaign studying $\mathrm{CH}_{4}$ emissions from the natural gas $\mathrm{G} \& \mathrm{P}$ facilities between October 2013 and April 2014. Dual-tracer flux measurements and on-site observations were used to address the magnitude and origins of $\mathrm{CH}_{4}$ emissions from these facilities. The use of a second tracer as an internal standard revealed plume-specific uncertainties in the measured emission rates of $20-47 \%$, depending upon plume classification. Combining downwind methane, ethane $\left(\mathrm{C}_{2} \mathrm{H}_{6}\right)$, carbon monoxide $(\mathrm{CO})$, carbon dioxide $\left(\mathrm{CO}_{2}\right)$, and tracer gas measurements with on-site tracer gas release allows for quantification of facility emissions and in some cases a more detailed picture of source locations.
\end{abstract}

\section{Introduction}

The natural gas industry has undergone a transformation in recent years, largely due to technological advancements such as hydraulic fracturing and horizontal drilling. These advances have led to increases in domestic natural gas production (EPA, 2014b), although concomitant with this increase has been a rising concern over methane emissions from the entire natural gas system from the perspective of both environmental impact and a loss of resources or product. Over the past decade, many studies have aimed at quantifying these emissions using a variety of methods, yielding a wide range of methane loss rate assessments for various sectors and basins from $<0.5 \%$ to greater than $10 \%$ (Pétron et al., 2012a and b; Allen et al., 2013; Karion et al., 2013; Bullock and Nettles, 2014; Subramanian et al., 2014; Zimmerle et al., 2014; Harrison et al., 2011; Zavala-Araiza et al., 2014).

The path of natural gas from well to the consumer can be considered in terms of five possible steps: production, gathering, processing, transmission and storage, and distribution. A recent series of studies have investigated $\mathrm{CH}_{4}$ emissions from each of these activities (Subramanian et al., 2014; Zimmerle et al., 2014; Allen et al., 2013). Presented here is a discussion of the methods used during one such investigation in which tracer release techniques were used to study emissions from gathering and processing (G\&P) facilities (Mitchell et al., 2015; Marchese et al., 2015). This approach is similar to that employed in previous field measurements of distribution, 
production, transmission, and storage facilities (Allen et al., 2013; Subramanian et al., 2014; Lamb et al., 2015). Of particular emphasis in this report are the measurement approach to the field campaign and the unique emission profiles associated with gathering and processing, illustrating the wide variety of handling, treating, and processing tools at the disposal of the natural gas industry. The G\&P field campaign was executed by Aerodyne Research, Inc. (ARI), Carnegie Mellon University (CMU), and Colorado State University from October 2013 through April 2014. Mobile laboratories operated by ARI and CMU sampled emissions from a total of $130 \mathrm{G} \& \mathrm{P}$ facilities across 20 natural gas basins in 13 states, using tracer release methodology as discussed below. The measurements were performed with cooperation from industry partners, who provided site access and detailed facility data, such as natural gas throughput, gas type, gas composition, equipment inventories, compressor power, age, and inlet/outlet pressures. Efforts were made by the study participants to ensure that the facilities were sampled as found, and the resulting data were assigned random numbers such that they cannot be traced back to a specific facility or partner company.

The inherent chemical profile of natural gas from different sources can significantly affect the technological approach that G\&P facilities use to prepare the gas for delivery into the transmission pipeline system. In order to sample from the wide range of equipment employed during gathering and processing, the campaign measured emissions from facilities associated with a variety of types of gas, such as gas with low- and high- $\mathrm{C}_{2+}$ hydrocarbon content (here referred to as dry and wet gas, respectively), as well as sour (high sulfur and/or $\mathrm{CO}_{2}$ content) and sweet gas sources (low sulfur and/or $\mathrm{CO}_{2}$ content). More detailed information about site selection is presented by Mitchell et al. in the companion paper, "Measurement Results" (Mitchell et al., 2015). These facilities handled natural gas derived from a variety of origins, including shale, coal-bed, and conventional wells. In many cases, the emission profiles associated with these facilities reflect the equipment used to prepare the natural gas (EIA, 2006; Kidnay et al., 2011). For example, the first step during gathering is often passage through gathering lines and a compressor (gathering) station. One of the primary purposes of gathering facilities is to collect and compress the input stream of gas to pipeline pressures, usually $\sim 800 \mathrm{psi}(\sim 55 \mathrm{bar})$. This requires the use of compressors and associated equipment, for which there are multiple possible emission sources such as compressor seals, natural-gas-driven pneumatic devices, and engine exhaust. Frequently gathering facilities will also remove water from the gas stream using dehydration trains, which provide more possible emissions points. Following gathering, sweet, dry gas can typically be easily conditioned and sent to the distribution network. However, gas that is sour, wet, or with a high water content requires significant subsequent processing, such as the removal of natural gas liquids (NGLs) using forced extraction, and sometimes a dehydration step to further remove water (Kidnay et al., 2011; Jumonville, 2010). These relatively complex structures can involve distillation columns, turboexpanders, separators, compressors, pneumatic devices, and heat exchangers, all of which can emit $\mathrm{CH}_{4}$ either through minor fugitive components or venting. Finally, extracted natural gas can have high $\mathrm{CO}_{2}$ and/or $\mathrm{H}_{2} \mathrm{~S}$ content (i.e., sour, especially in coal-bed methane and some shale-gas regions), which requires amine treating (frequently collocated with other gas processing or compression facilities) to make it distribution-ready (Kidnay et al., 2011). Again, this equipment and additional processing adds to the number of possible emission sources.

Presented in the second half of this paper are examples of the unique chemical profiles associated with the gathering, treatment, and processing systems utilized by the natural gas industry. In the process of measuring $\mathrm{CH}_{4}$ emission rates, these signatures can provide important information about contributions from specific methane sources on site.

\section{Challenges in measuring emissions from natural gas facilities}

The necessity for emissions measurements at natural gas facilities is two-fold: (i) as an assessment of the impact of facility operation upon regional and national air quality and climate (EPA, 2014a) and (ii) to quantify losses due to normal operation or identify large emission sources. In the case of (i), measured emissions provide an opportunity to compare to national estimates and assess the overall impact of the natural gas supply chain on $\mathrm{CH}_{4}$ emissions in the US. (Marchese et al., 2015; Subramanian et al., 2014). In the case of (ii), these measurements aid the natural gas industry in minimizing product losses.

\subsection{Bottom-up approaches}

Several approaches have been utilized to observe emissions at industrial facilities. In some cases, a bottom-up approach is employed, wherein the magnitudes of emissions from individual components are directly measured and then added together to estimate the facility-level emission rate (FLER) (Subramanian et al., 2014; Harrison et al., 2011). This makes use of stack test data, manufacturer data, emission factors, engineering estimates, activity factors, and onsite measurements. These on-site measurements can take many forms, such as acoustic emission detection, which quantifies leaks through suspected leak points such as valves, and Hi-Flow ${ }^{\circledR}$ sampling, which can accurately determine emission rates from a variety of fixtures. While these methods are widely used and are capable of many measurements in a short time, they are not applicable to all possible emission sources due to the number and accessibility of fixtures within facilities (Subramanian et al., 2014). This issue is particularly relevant at large processing and treating 
plants, where the inability to measure emissions from a large number of components could lead to an asymmetric bias in the reported FLER. In addition, in order to accurately scale bottom-up studies to nationwide (or even regional) estimates, care must be taken to ensure that the sampled population, which is typically small, accurately represents the national or regional inventory of facilities.

Optical gas imaging (e.g., infrared cameras such as FLIR $^{\circledR}$ ) is a method by which leaks can be identified by using real-time infrared imaging. This method provides a high duty cycle - dozens of fixtures within a facility can be investigated per hour - and large emitters can be readily identified. It is often used in conjunction with the above methods to locate possible leak sources. However, because the method does not measure $\mathrm{CH}_{4}$ concentrations or flow rates, it does not quantify the emission magnitudes. It nonetheless serves as a powerful qualitative tool in leak detection and is therefore leveraged in this study to identify suspected emission points at each G\&P facility.

\subsection{Top-down approaches}

Top-down estimates aim to quantify methane emissions from a particular geographic region. These results can then be compared to inventories constructed from bottom-up measurements. Two top-down approaches are commonly used for determining regional methane emissions: mass-balance flights and fixed sensors fields (Zavala-Araiza et al., 2014). The mass-balance flight method, exemplified in several recent oil and gas basin studies (Karion et al., 2013; Pétron et al., 2012b, 2013), uses upwind and downwind transects to capture emissions from a bounded region. This area can be as small as an individual facility or as large as an entire basin. Under favorable meteorological conditions, such measurements can potentially estimate emissions from a large area with a single flight, but these techniques are costly and provide little to no source-specificity. This lack of sourcespecificity makes it especially difficult for top-down studies to determine the relative emissions from various activities within the industry (i.e., from gathering, processing, transmission, or production) or even differentiate between emissions from different industries, such as natural gas vs. feedlots vs. farming operations vs. natural emissions. In addition, due to costs, these studies have a limited number of samples over a short duration (hours) and therefore may not be representative of actual emissions when extrapolated and compared with annual nationwide inventories.

Top-down estimates of regional emissions are also commonly performed using meteorological transport simulations in combination with a network of fixed sensors or using inverse modeling coupled with dispersion or advection models (Wofsy, 2013; Bullock and Nettles, 2014; Zavala-Araiza et al., 2014). Such methods can leverage preexisting sensor networks with data available $24 \mathrm{~h} \mathrm{day}^{-1}$. However, the interpretation of sensor data for emissions measurements is highly dependent upon atmospheric modeling, with large uncertainties (Nehrkorn et al., 2010; Draxler and Hess, 1997, 1998).

\subsection{Tracer release approach}

Because the goal of this study was to develop an understanding of the total emissions from individual G\&P facilities and to use these measurements to estimate total national emissions from natural gas gathering and processing (Marchese et al., 2015), the measurement approach described here uses an established measurement technique called tracer flux ratio (or tracer ratio). It has previously been demonstrated that the tracer ratio method can quantify the total emissions from industrial sites (Lamb et al., 1995; Allen et al., 2013) and landfills (Czepiel et al., 1996; Mosher et al., 1999). The strengths of the method are that it does not require theoretical modeling, can measure facility-wide emissions, and under the proper conditions can be useful in identifying large sources within a facility. The tracer ratio method has been shown to effectively and accurately yield the total emissions from many small sources within a large area, where measurements of individual leak rates would be challenging (Shorter et al., 1997; Mosher et al., 1999; Subramanian et al., 2014; Lamb et al., 1995). It therefore allows for FLERs to be determined for large facilities such as processing and treatment plants, where a multitude of possible emissions sources exist that may not be accessible or quantifiable using bottom-up approaches. For this study, the method is applied to quantify total facility-level methane emission rates (fugitive, venting, and combustion) at natural gas processing plants, treatment facilities, and midstream compressor stations.

Conceptually, the tracer release method is based upon the simple relation that the downwind concentration enhancement of gas $X$ above ambient background, $\Delta[X]$, is directly related to the flow rate at its source, $F_{X}$ :

$\Delta[X]=\alpha \cdot F_{X}$.

The relation between these two quantities is determined by $\alpha$. The coefficient $\alpha$ is a complicated function of meteorological information, such as wind speed, wind history, turbulence, solar irradiance, temperature, boundary layer height, local topography, and downwind distance. In principle this information can be estimated using, for example, a Gaussian dispersion model (Beychok, 2005). Such models have had success in qualitatively reproducing measured plume data but frequently lack the precision and accuracy required for this study, especially in areas with complex terrain and meteorology.

The tracer release method provides an empirical means to bypass the need for determining $\alpha$ (Lamb et al., 1986, 1995). By deploying a known flow of tracer gas located physically near a $\mathrm{CH}_{4}$ emission source, the downwind tracer concentration enhancement (above background), $\Delta[T]$, downwind $\mathrm{CH}_{4}$ concentration enhancement (above background), $\Delta\left[\mathrm{CH}_{4}\right]$, and tracer flow rate, $F_{T}$, become measurable quan- 


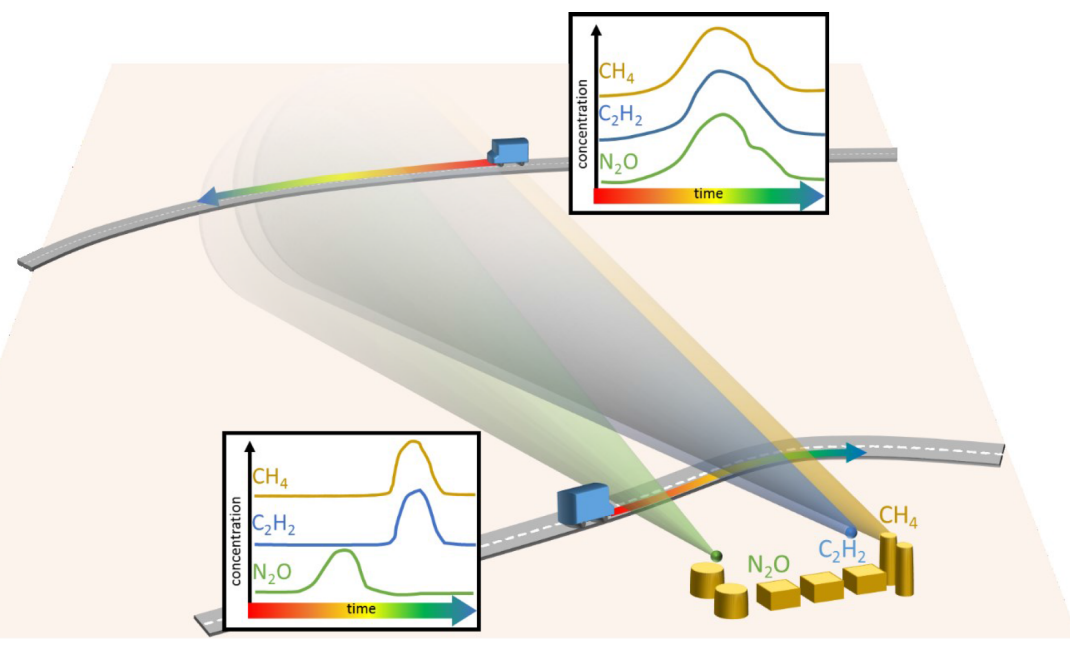

Figure 1. Schematic of dual-tracer release technique. At distances far downwind (top), both tracers and $\mathrm{CH}_{4}$ are spatiotemporally overlapped. At distances closer to the facility, the spatial position of the $\mathrm{CH}_{4}$ plume relative to the two tracer plumes can indicate the location of an emission vector on-site with sub-facility resolution.

tities. The ratio of the two downwind concentrations is then equal to the ratio of flow rates:

$\frac{\Delta\left[\mathrm{CH}_{4}\right]}{\Delta[T]}=\frac{\alpha}{\alpha} \frac{F_{\mathrm{CH}_{4}}}{F_{T}}=\frac{F_{\mathrm{CH}_{4}}}{F_{T}}$

where $F_{\mathrm{CH}_{4}}$ refers to the flow of $\mathrm{CH}_{4}$ from the facility. Because concentrations $\Delta\left[\mathrm{CH}_{4}\right]$ and $\Delta[T]$ are measured and $F_{T}$ is known, $F_{\mathrm{CH}_{4}}$ can be determined without the need for detailed information about $\alpha$.

The underlying assumption in this technique is that the tracer release point is located close enough to the unknown emission source that both gases experience the same dilution factor $\alpha$. This separation distance becomes less important as the concentration measurement (aboard a mobile platform) moves further downwind. However, when the separation distance is of the same order as the downwind distance, the $\alpha$ values associated with $\mathrm{CH}_{4}$ and $T$ are expected to be significantly different. Under ideal circumstances, the tracer is collocated with the emission source, and their concentrations are measured far downwind in stable meteorological conditions. In practice this is not always possible due to facility size, interfering methane sources, road access, or varying winds.

To mitigate these issues, this study made use of a dualtracer release technique (Allen et al., 2013) in which two different tracer gases, in this case $\mathrm{N}_{2} \mathrm{O}$ and $\mathrm{C}_{2} \mathrm{H}_{2}$, are released from different locations within the facility, bracketing the on-site equipment, as shown in Fig. 1. The use of a second tracer has two important advantages over single-tracer measurements. First, closer downwind measurements (50$200 \mathrm{~m}$ downwind) afford a refined assessment of an emission source location based upon the position of its $\mathrm{CH}_{4}$ plume relative to each tracer plume. Second, when conducting mixed plume characterization in the far-field (downwind), where $\alpha_{\mathrm{N}_{2} \mathrm{O}} \sim \alpha_{\mathrm{C}_{2} \mathrm{H}_{2}} \sim \alpha_{\mathrm{CH}_{4}}$, the second tracer becomes an inter- nal standard to the measurement. This capability mitigates the need for a calibration or for benchmarking against other measurements. Emissions rates determined by tracer release have, however, been compared to detailed on-site leak measurements in Subramanian et al. (2014). That study found that these two techniques usually agreed to within experimental uncertainty. The use of two known tracer gas flow rates and an observed downwind molar ratio also provides an empirical measure of the uncertainty for every plume. This error will be further described below, in the Supplement, and in the associated Measurements report (Mitchell et al., 2015).

\subsection{Understanding and optimizing data quality}

In the context of the two possible transect scenarios depicted in Fig. 1 (spatially overlapping plumes vs. spatially separated plumes), it is important to qualitatively understand what measurement conditions (tracer separation, transect distance, meteorology) yield these two results. This can be developed using Gaussian dispersion modeling as a guide (Beychok, 2005). As a rule of thumb, for typical mid-day atmospheric conditions (stability classes A, B, or C, as described in the Supplement) and downwind distances (100-3000 m), the horizontal width of a plume that is propagating according to Gaussian dispersion is $\sim 20-50 \%$ of the distance that it has traveled from its source. That is, the ratio of plume width to downwind distance is $0.2-0.5$, where low wind conditions yield wider plumes $(\sim 0.5)$ and high wind conditions yield narrower plumes $(\sim 0.2)$. A plume observed $1000 \mathrm{~m}$ downwind of its origin, for example, is typically $200-500 \mathrm{~m}$ wide.

If the plume widths of two gases being measured downwind (e.g., $\mathrm{CH}_{4}$ and $\mathrm{N}_{2} \mathrm{O}$ ) are much larger than the separation of their sources, the plumes will generally be codispersed or spatially overlapping. Therefore the ratio of the 
distance between emission sources to the downwind transect distance must be less than $0.2-0.5$ in order to achieve co-dispersion. When, for example, the separation between an $\mathrm{N}_{2} \mathrm{O}$ tracer and a $\mathrm{CH}_{4}$ source is $100 \mathrm{~m}$, the downwind distance required to observe the onset of co-dispersion is $>500 \mathrm{~m}$ in high winds and $>200 \mathrm{~m}$ in low winds. Alternatively, when local road access limits the downwind distance to $200-500 \mathrm{~m}$, the $\mathrm{N}_{2} \mathrm{O}$ tracer must be placed within $100 \mathrm{~m}$ of the suspected $\mathrm{CH}_{4}$ emission source.

This same rule-of-thumb approach can be applied to cases where a nearby $\mathrm{CH}_{4}$ source, such as a wellhead, may interfere with the FLER measurement at a G\&P facility. In these cases, the downwind transect must be close enough that the interfering plume width is smaller than its separation from the G\&P facility. For example, if the distance between a wellhead and facility is $50 \mathrm{~m}$, downwind transects must be less than $100-250 \mathrm{~m}$ in order isolate and exclude the wellhead plume from the FLER estimate.

When the second tracer is used as an internal standard, it can serve to quantify the uncertainty of the measurement. As will be shown below and in the Supplement, this uncertainty decreases when the two tracer plumes are spatially overlapping compared to cases where the plumes are separated. Because this precision reflects the uncertainty in the FLER, efforts are made by the study team to maximize the codispersion of methane and tracer plumes. In light of the above discussion, this can be achieved by attempting to place one or both tracers near the dominant suspected emission source at a facility, when one exists. When these conditions are met, the downwind distance required to observe co-dispersion is reduced, thereby increasing the instrumental signal-to-noise and further separating any possible interfering sources.

Initial placement of the tracers at opposite ends of the facility allows for early transects to identify suspected methane emission locations. In some cases, the observed methane plume will appear covariant with one of the two tracers, indicating that the dominant methane emitter is in the vicinity of that tracer. In many cases, however, the methane plume is observed between the two tracer plumes. In this scenario, one (or both) of the tracers is typically moved such that its plume is spatially overlapping the methane plume. This process is iterated multiple times over the course of the measurement in order to yield plumes that exhibit high degrees of $\mathrm{CH}_{4}$-totracer correlation.

While two tracers act as an internal standard in the horizontal plane, a complicating factor unique to some large facilities (e.g., processing plants and larger gathering facilities) studied here is the presence of flares and/or engine exhaust stacks, some of which can be over $20 \mathrm{~m}$ tall. Presented in the Supplement is a Gaussian plume and Brigg's equation analysis of the effect of a possible elevated $\mathrm{CH}_{4}$ source on the measured emission rate (Beychok, 2005). A simple rule-of-thumb approach as used above is hampered here by both buoyant plume rise effects and plume reflection off of the ground. These calculations indicate that in strong wind conditions (i.e., high atmospheric stability classes, such as in winds above $5 \mathrm{~m} \mathrm{~s}^{-1}$ ), the measured emission rate determined from close transects can be biased considerably low, depending upon the fraction of the emission coming from elevated positions. In wind conditions below $5 \mathrm{~m} \mathrm{~s}^{-1}$, the dispersion is large enough that the bias is lessened to $0-50 \%$. To minimize this bias, plumes were obtained as far downwind as possible, and at several processing plants a tracer was emitted at an elevated position such as the side of a demethanizer column or stack. The impact of the bias upon the overall data set and resulting conclusions is discussed in more detail in the accompanying Measurements paper (Mitchell et al., 2015).

\subsection{Auxiliary species}

The study team also used measurements of other species, $\mathrm{CO}, \mathrm{CO}_{2}$, and $\mathrm{C}_{2} \mathrm{H}_{6}$, to aid in identifying and attributing methane emissions to targeted G\&P facilities. For example, engine exhaust from reciprocating engines and turbines that power compressors at many natural gas facilities will contain $\mathrm{CO}$ and $\mathrm{CO}_{2}$. This enables potential differentiation between emissions of G\&P equipment and those emanating from nearby well pads (which typically do not include combustion sources or emit much smaller amounts of $\mathrm{CO}$ and $\mathrm{CO}_{2}$ ). Similarly, amine treatment systems serve as noncombustion sources of $\mathrm{CO}_{2}$ and are easily distinguishable from other facilities (Rochelle, 2009; EIA, 2006; Kidnay et al., 2011).

Ethane measurements serve multiple purposes within the context of this study. First, the presence of ethane associated with methane in downwind plumes indicates that some fraction of the methane is of thermogenic, rather than biogenic, origin. The ability to distinguish between these sources is especially important in farming and ranching regions, where livestock emissions can be a substantial source of $\mathrm{CH}_{4}$. Second, the observed ethane-to-methane ratio ( $\mathrm{E} / \mathrm{M}$ ratio) in a downwind plume can serve as a unique identifier of a facility of interest. It can therefore be used to differentiate a particular emission source from others in the area. Finally, variations in ethane content over close transects can indicate active distillation or other processing present on-site. The utility of these measurements will be explicitly illustrated via examples in the Results section.

\section{Laboratory and instrument details}

The two mobile laboratories used in this study were operated by Aerodyne Research, Inc. (Herndon et al., 2005) and Carnegie Mellon University (Subramanian et al., 2014). Both mobile laboratories contain a variety of spectroscopybased gas-detection instruments, which sample the ambient air from an inlet mounted on the front of the vehicle. In the case of the Aerodyne mobile laboratory, three ARI direct-absorption quantum cascade laser (QCL) spectrometers (Jiménez et al., 2005; Yacovitch et al., 2014; McManus 
Table 1. Instruments and sensitivities for measured species on Aerodyne and CMU mobile laboratories.

\begin{tabular}{|c|c|c|}
\hline Instrument & Species detected & Sensitivity \\
\hline \multicolumn{3}{|c|}{ Aerodyne mobile laboratory } \\
\hline \multirow[t]{2}{*}{ Aerodyne dual QCL } & $\mathrm{CH}_{4}$ & $1 \mathrm{ppb}$ \\
\hline & $\mathrm{C}_{2} \mathrm{H}_{2}$ & $200 \mathrm{ppt}$ \\
\hline Aerodyne mini QCL & $\mathrm{C}_{2} \mathrm{H}_{6}$ & $100 \mathrm{ppt}$ \\
\hline \multirow{2}{*}{ Aerodyne mini QCL } & $\mathrm{N}_{2} \mathrm{O}$ & $100 \mathrm{ppt}$ \\
\hline & $\mathrm{CO}$ & $100 \mathrm{ppt}$ \\
\hline Li-Cor NDIR & $\mathrm{CO}_{2}$ & $500 \mathrm{ppb}$ \\
\hline \multicolumn{3}{|c|}{ Carnegie Mellon mobile laboratory } \\
\hline \multirow[t]{2}{*}{ Picarro CRDS } & $\mathrm{CH}_{4}$ & $3 \mathrm{ppb}$ \\
\hline & $\mathrm{C}_{2} \mathrm{H}_{2}$ & $600 \mathrm{ppt}$ \\
\hline \multirow[t]{3}{*}{ Aerodyne dual QCL } & $\mathrm{C}_{2} \mathrm{H}_{6}$ & $100 \mathrm{ppt}$ \\
\hline & $\mathrm{N}_{2} \mathrm{O}$ & $100 \mathrm{ppt}$ \\
\hline & $\mathrm{CO}$ & $100 \mathrm{ppt}$ \\
\hline
\end{tabular}

et al., 2005) operating at 20-40 Torr are employed in series to detect $\mathrm{CH}_{4}, \mathrm{C}_{2} \mathrm{H}_{6}, \mathrm{CO}, \mathrm{N}_{2} \mathrm{O}$, and $\mathrm{C}_{2} \mathrm{H}_{2}$. To detect $\mathrm{CO}_{2}$, a non-dispersive infrared (NDIR) LiCOR ${ }^{\circledR}$ instrument is used. In this work, the QCL spectrometers are operated in series, with flow rates through the instruments of $\sim 10$ SLPM. This flow rate afforded a time response of $<1 \mathrm{~s}$. The NDIR instrument draws a small flow from the inlet line before the air sample entered the QCLs. The QCL spectrometers report mixing ratios of all species in parts per billion by volume (ppbv), while the NDIR instrument reports $\mathrm{CO}_{2}$ in parts per million by volume (ppmv). In the Carnegie Mellon mobile laboratory, $\mathrm{CH}_{4}$ and $\mathrm{C}_{2} \mathrm{H}_{2}$ are measured using a Picarro cavity ring-down spectrometer (Crosson, 2008; Rella et al., 2009) running at $4-5 \mathrm{~Hz}$, while $\mathrm{C}_{2} \mathrm{H}_{6}, \mathrm{~N}_{2} \mathrm{O}$, and $\mathrm{CO}$ are measured using an ARI Dual QCL spectrometer operating at $1 \mathrm{~Hz}$. Detection limits of all instruments are listed in Table 1. Except for practically limiting the minimum detectable concentration of certain species, the differences in equipment manufacturer and sensitivity do not affect the results of the measurements. In addition to the concentration information, both mobile laboratories record their location, bearing, and heading using Global Positioning System (GPS; Garmin ${ }^{\circledR}$ 76 and Hemisphere GPS Compass ${ }^{\circledR}$ for the ARI laboratory, Airmar ${ }^{\circledR}$ for the CMU laboratory). A small meteorological station (Airmar ${ }^{\circledR}$ 200WX or LB150) is also mounted on a boom at the front of the vehicle to record true wind speed (speed corrected for vehicle velocity), true wind direction (wind direction relative to true north), and GPS location. Along with the mixing ratios, this information is recorded at $1 \mathrm{~s}$ intervals on a main onboard acquisition computer, where all of the acquired data are visualized in real time and can be overlaid on maps.
Both laboratories are accompanied by a tracer release vehicle (i.e., pickup truck) to facilitate the storage, setup, and release of the $\mathrm{N}_{2} \mathrm{O}$ and $\mathrm{C}_{2} \mathrm{H}_{2}$ tracers. Tracer gas bottles are stored on the bed of the truck, along with flow control systems and associated valves, tubing, and telemetry systems. Polyethylene tubing for each tracer is rolled out from the pickup truck up to $200 \mathrm{~m}$ to the intended release location, where the end of the tube is attached to on-site equipment or placed on a tripod. For both laboratories, tracer flow rates are controlled by Alicat ${ }^{\circledR}$ MC-series mass flow controllers. The mass flow rates are recorded via RS232 to an onboard computer in the vehicle.

In addition to the tracer gas flow systems, three portable meteorological stations (Airmar ${ }^{\circledR}$ 200WX) are deployed on tripods, sometimes serving as physical supports for the tracer release tubing. They are capable of recording GPS, true wind direction, and wind speed with $1 \mathrm{~s}$ resolution. Each unit broadcasts that information wirelessly or via an RS232 cable at $1 \mathrm{~Hz}$ to a computer onboard the tracer release vehicle, where it is recorded and displayed for observation by the tracer release personnel to advise the mobile laboratory as needed. When considered in the context of tracer placement, the wind data can immediately inform mobile laboratory personnel whether a tracer is being deployed in an area on-site that is not well ventilated. If this is the case (frequently due to the local wind currents near buildings) the tracer can then be moved to allow it to be carried downwind by the larger regional wind mass. This information also provides a crude wind field for later analysis to better understand the sources of error and uncertainty in tracer release methods.

\section{Calibrations and ranges}

In both laboratories, the inlet was periodically overblown (injected with a flow larger than the intake flow) with ultra-zero air (AirGas ${ }^{\circledR}$ or Praxair ${ }^{\circledR}$ ) to zero the instruments, typically every $15 \mathrm{~min}$ for $30 \mathrm{~s}$. Because $\mathrm{CH}_{4}$ and $\mathrm{N}_{2} \mathrm{O}$ are present in background ambient air (1900 and 325 ppbv, respectively), zeroing events also serve as an approximate check of those instrument calibrations. Full instrument calibrations were performed several (4-5) times over the course of the measurement campaign using calibration standards. For these dilution calibrations, a controlled mass flow of calibration gas is released into a known zero-air flow, and the resulting mixture is overblown into the inlet. The mixture is changed by varying the calibration gas flow using either a series of critical orifices or mass flow controllers (Alicat ${ }^{\circledR}$ MC Series). Typical calibration ranges were $0-10 \mathrm{ppm}$ for $\mathrm{CH}_{4}$, $0-500 \mathrm{ppb}$ for $\mathrm{C}_{2} \mathrm{H}_{2}$, and $0-1000 \mathrm{ppb}$ for $\mathrm{N}_{2} \mathrm{O}$. The calibrations were linear, with typical $R^{2}>0.99$. The results of these calibrations changed less than $5 \%$ over the course of the campaign. The mass flow controllers onboard the tracer release vehicle are also periodically calibrated using a NISTtraceable Dry-Cal ${ }^{\circledR}$ flow meter. 


\section{Field implementation}

In practice, when the mobile laboratory arrived at a facility a safety meeting was conducted with the facility supervisor, after which the tracer release apparatuses were set up. The tracer positions were decided upon after discussion with the supervisor regarding likely emission sources (near compressors, dehydrators, tanks, etc.), a cursory survey with infrared imaging, consideration of the current wind conditions, site size and safety issues, and sometimes after performing an initial drive within facility boundaries. After setup, the tracer gases were released and the mobile laboratory was deployed downwind. Constant communication was maintained either over CB radio or cellular phones. During this period, an additional study team member ("the on-site observer") surveyed the facility with an infrared camera, inventoried facility components, and recorded relevant information such as facility throughput, equipment counts, and motor, engine, or turbine horsepower. In many cases the identification of emission sources by survey of the facility using infrared imaging agreed with or informed the results of close-pass plume transects. If the mobile laboratory detected $\mathrm{CH}_{4}$ plumes that were spatially separated from the tracer plumes, one or both tracers were moved to maximize co-dispersion with $\mathrm{CH}_{4}$. When possible, on-site ethane-to-methane ratios were measured by driving the mobile laboratory within fence line immediately downwind $(<25 \mathrm{~m})$ of on-site equipment, for future comparison with partner company gas chromatograph (GC) data.

After acquiring enough downwind plumes (a target of 10) to provide a statistically meaningful time-averaged FLER and uncertainty, the mobile laboratory returned on-site, and the tracer release hardware was packed. Usually at least two facilities were surveyed daily and sometimes as many as four, depending upon wind conditions, time, and the locations of nearby facilities. Because of their size and scale, a full day was reserved to sample emissions from processing facilities.

\section{Plume types and analysis methods}

There are multiple ways in which downwind tracer plumes can be analyzed, depending upon the plume intensity and spatial overlap between the tracer and $\mathrm{CH}_{4}$ plumes (Subramanian et al., 2014). Figures 2-5 show the four possible plume types observed during the G\&P campaign.

\subsection{Dual correlation}

The ideal scenario occurs when the measurement transect is far enough downwind of the facility that the $\mathrm{CH}_{4}, \mathrm{~N}_{2} \mathrm{O}$, and $\mathrm{C}_{2} \mathrm{H}_{2}$ plumes are spatially overlapping. The resulting measurements of concentration vs. time exhibit a high degree of covariance between species, as shown in the top panel of Fig. 2. Analysis of these "dual-correlation" plumes consists of plotting the concentration of one species vs. another and performing a linear orthogonal distance regression fit as shown in the bottom panels of Fig. 2. This regression analysis is performed for $\mathrm{CH}_{4}$ vs. $\mathrm{N}_{2} \mathrm{O}, \mathrm{CH}_{4}$ vs. $\mathrm{C}_{2} \mathrm{H}_{2}, \mathrm{~N}_{2} \mathrm{O}$ vs. $\mathrm{C}_{2} \mathrm{H}_{2}$, and $\mathrm{C}_{2} \mathrm{H}_{6}$ vs. $\mathrm{CH}_{4}$. From these linear regressions, the slope indicates the ratio of concentrations of the two gas species (for use in Eq. 2), and $R^{2}$ indicates the degree of correlation. These values are recorded for use in determining whether the plume meets the acceptance criteria for the $\mathrm{CH}_{4}$ emission rate to be considered valid. If the $R^{2}$ values derived from fits of $\mathrm{CH}_{4}$ vs. $\mathrm{N}_{2} \mathrm{O}, \mathrm{CH}_{4}$ vs. $\mathrm{C}_{2} \mathrm{H}_{2}$, and $\mathrm{N}_{2} \mathrm{O}$ vs. $\mathrm{C}_{2} \mathrm{H}_{2}$ are all greater than 0.75 , and the tracer ratio $\left(\left[\mathrm{C}_{2} \mathrm{H}_{2}\right] /\left[\mathrm{N}_{2} \mathrm{O}\right]\right)$ is within a factor of 1.5 of the known tracer flow rate, the plume is a candidate for dual-correlation analysis. The choice of acceptable $R^{2}$ and tracer ratio were based upon values at which further relaxation of the criteria would alter the uncertainty and accuracy of the FLER measurement (Mitchell et al., 2015). A discussion of the use of a factor for the tracer ratio criterion, as opposed to a deviation such as $\pm 50 \%$, is presented in the Supplement.

\subsection{Dual area}

In certain circumstances, wind conditions along with local road access and intervening $\mathrm{CH}_{4}$ sources prevent the ability to get far enough downwind for the tracer gas and $\mathrm{CH}_{4}$ plumes to become spatially overlapped. However, transects may still be performed closer to the facility $(\sim 50-500 \mathrm{~m})$ such that all three species will be observed. As illustrated in the example shown in Fig. 3, under these circumstances correlation diagrams do not provide useful information about the ratio of species (bottom panels). In these cases a "dualarea" technique is used, in which the analysis must rely on the integrated area of each species' plume over the time of the transect. Here, the deviation of the species' mixing ratios from ambient conditions must be considered, rather than the raw integrated intensity. This point is particularly relevant for $\mathrm{CH}_{4}$ and $\mathrm{N}_{2} \mathrm{O}$, whose ambient concentrations are $\sim 1900$ and $\sim 325 \mathrm{ppb}$, respectively. In the analysis of the data, the baseline (non-plume) mixing ratio was determined by fitting a line through the average of several data points immediately before the plume transect began and the average immediately after the transect ended. The fit line was then subtracted from the data to yield a baseline-corrected plume. This accounted not only for background concentrations (e.g., 1900 or $325 \mathrm{ppb}$ ) but also any minor baseline drift that may have occurred over the course of the transect. The quality of the baseline fit was visually confirmed and corrected if it did not accurately represent the true baseline. For the plume to be considered a candidate for dual-area analysis, the ratio of areas of the $\mathrm{C}_{2} \mathrm{H}_{2}$ and $\mathrm{N}_{2} \mathrm{O}$ plumes must be within a factor of 2 of the known tracer flow rates.

\subsection{Single correlation}

In scenarios where the $\mathrm{CH}_{4}$ mixing ratio was highly correlated with only one of the two tracers, a "single-correlation" analysis was performed, as shown in Fig. 4. This approach 

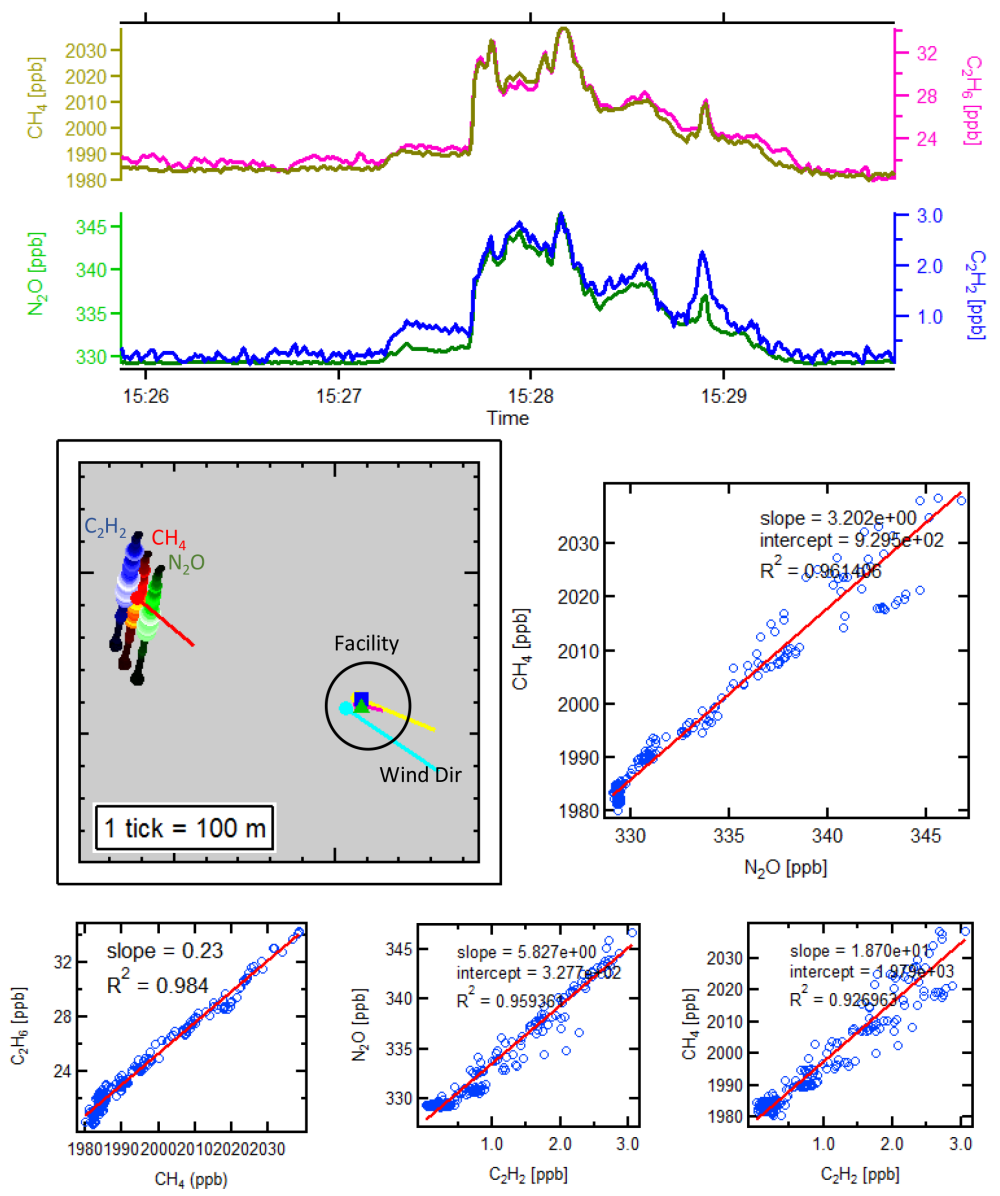

Figure 2. Example dual-correlation plume from a natural gas facility. Top panel: time trace of $\mathrm{CH}_{4}, \mathrm{C}_{2} \mathrm{H}_{6}, \mathrm{~N}_{2} \mathrm{O}$, and $\mathrm{C}_{2} \mathrm{H}_{2}$ concentrations, showing high temporal correlation. Center left panel: map of tracer location (right side) and transect location (left side) during the course of the plume. Red, blue, and green weighted lines correspond to $\mathrm{CH}_{4}, \mathrm{C}_{2} \mathrm{H}_{2}$, and $\mathrm{N}_{2} \mathrm{O}$ intensities during the transect, spatially offset for clarity. Thin lines point into the wind at the mobile laboratory (red) and at the facility (light blue, pink, and yellow). Blue square and green triangle indicate $\mathrm{C}_{2} \mathrm{H}_{2}$ and $\mathrm{N}_{2} \mathrm{O}$ release locations, respectively. Lower panels: Correlation analysis of $\mathrm{C}_{2} \mathrm{H}_{6}$ vs. $\mathrm{CH}_{4}, \mathrm{~N}_{2} \mathrm{O}$ vs. $\mathrm{C}_{2} \mathrm{H}_{2}, \mathrm{CH}_{4}$ vs. $\mathrm{C}_{2} \mathrm{H}_{2}$, and $\mathrm{CH}_{4}$ vs. $\mathrm{N}_{2} \mathrm{O}$. The measured emission rate from this plume was found to be 3.4 SCFM.

corresponds to that originally used by Lamb et al. in early demonstrations of the tracer release method (Lamb et al., 1995). The need to use the single-correlation technique can be the consequence of several possible measurement conditions: (i) one of the tracers is placed geographically close to the dominant emitter within the facility (e.g., a compressor or large fugitive source), (ii) the site is emitting a tracer species (i.e., $\mathrm{C}_{2} \mathrm{H}_{2}$ during certain combustion processes), forcing the measurement to become single-tracer only, or (iii) the plume transect is far enough downwind (frequently $>2 \mathrm{~km}$ ) that one of the tracer species' mixing ratio is at or below the instrumental detection limit. In single-correlation cases, correlation analysis is performed for both tracers but only the well-correlated tracer serves to provide the true $\mathrm{CH}_{4}$ emission rate. For a plume to be a candidate for single-correlation analysis, the $R^{2}$ value derived from the linear regression fit of $\mathrm{CH}_{4}$ to one of the two tracers must be greater than 0.75 .

\subsection{Linear combination of tracer plumes}

In certain circumstances, unique tracer placement, road access, and wind conditions allow for intermediate-distance transects where the $\mathrm{CH}_{4}$ plume profile is not well correlated with either individual tracer but is well correlated with a linear combination of the tracer plumes, i.e.,

$\Delta\left[\mathrm{CH}_{4}\right]=a \cdot \Delta\left[\mathrm{N}_{2} \mathrm{O}\right]+b \cdot \Delta\left[\mathrm{C}_{2} \mathrm{H}_{2}\right]$,

where $\mathrm{a}$ and $\mathrm{b}$ are multiplicative coefficients of the $\mathrm{N}_{2} \mathrm{O}$ and $\mathrm{C}_{2} \mathrm{H}_{2}$ plumes, respectively. Such an example is shown in Fig. 5. This scenario is equivalent to performing two independent single-tracer measurements, where the plumes are overlapping in time. In these cases facility emission rates can be determined by performing a correlation analysis of $\mathrm{CH}_{4}$ vs. $\left(a \cdot \Delta\left[\mathrm{N}_{2} \mathrm{O}\right]+b \cdot \Delta\left[\mathrm{C}_{2} \mathrm{H}_{2}\right]\right)$ while adjusting the values of $a$ and $b$ in Eq. (3). The $a$ and $b$ values that provide the largest possible $R^{2}$ value in the fit are used to determine 

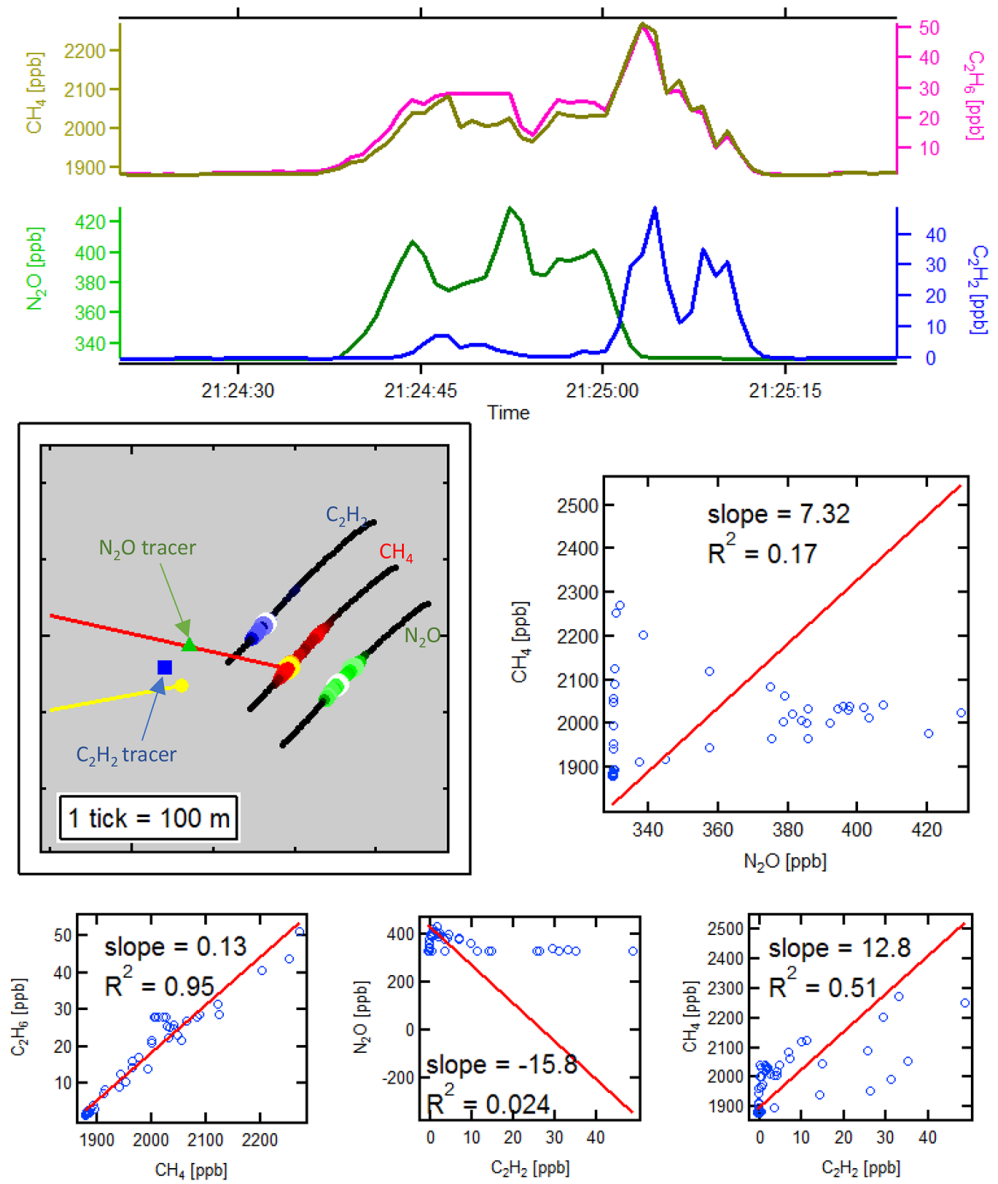

Figure 3. Similar to Fig. 2, illustrating dual-area-type plumes. Top panel: time trace of $\mathrm{CH}_{4}, \mathrm{C}_{2} \mathrm{H}_{6}, \mathrm{~N}_{2} \mathrm{O}$, and $\mathrm{C}_{2} \mathrm{H}_{2}$ concentrations, showing high temporal correlation. Center left panel: map of tracer location (right side) and transect location (left side) during the course of the plume. Red, blue, and green weighted lines correspond to $\mathrm{CH}_{4}, \mathrm{C}_{2} \mathrm{H}_{2}$, and $\mathrm{N}_{2} \mathrm{O}$ intensities during the transect, spatially offset for clarity. Thin lines point into the wind at the mobile laboratory (red) and at the facility (light blue, pink, and yellow). Blue square and green triangle indicate $\mathrm{C}_{2} \mathrm{H}_{2}$ and $\mathrm{N}_{2} \mathrm{O}$ release locations, respectively. Lower panels: correlation analysis of $\mathrm{C}_{2} \mathrm{H}_{6}$ vs. $\mathrm{CH}_{4}, \mathrm{~N}_{2} \mathrm{O}$ vs. $\mathrm{C}_{2} \mathrm{H}_{2}, \mathrm{CH}_{4}$ vs. $\mathrm{C}_{2} \mathrm{H}_{2}$, and $\mathrm{CH}_{4}$ vs. $\mathrm{N}_{2} \mathrm{O}$. Note the lack of correlation in lower left and center panels, indicating that the analysis must rely on an area method. Note, however, the strong correlation between $\mathrm{C}_{2} \mathrm{H}_{6}$ and $\mathrm{CH}_{4}$ (bottom left), indicating that the observed methane is derived from natural gas. The emission rate determined from this plume was found to be 3.1 SCFM.

the $\mathrm{CH}_{4}$ emission rate associated with each tracer. While the sum of these values serves as the FLER, the individual emission rates contain information at sub-facility-level resolution, such as leak or vent magnitudes associated with condensate tanks, compressors, or dehydrators.

This analysis method has also been applied in cases where equipment not associated with the G\&P (e.g., a natural gas production well) is present within a facility boundary. In such a case, one tracer is placed at or near the non-associated equipment while the other is placed near a suspected emitter that is part of G\&P facility. If the plume from the former tracer is well correlated with the non-associated equipment emission and the plume from the latter tracer is well correlated with the rest of the $\mathrm{CH}_{4}$ from the facility of interest, then the facility level emission rate can be estimated, even when the $\mathrm{CH}_{4}$ from the non-associated equipment is overlapping with the facility plume.

\subsection{Implementation of plume analysis}

Table 2 summarizes the preference of the four analysis methods, their acceptance criteria, the number of accepted plumes that were analyzed using each method, and the measurement variance associated with each plume type. The determination of the variance for each plume type is discussed in detail in the Supplement.

The large number of plumes observed during the measurement campaign allows for extensive statistical analysis of dual correlation, dual area, and single-correlation plumes. As is discussed in the Supplement and the associated Measurements report (Mitchell et al., 2015), this statistical analysis 

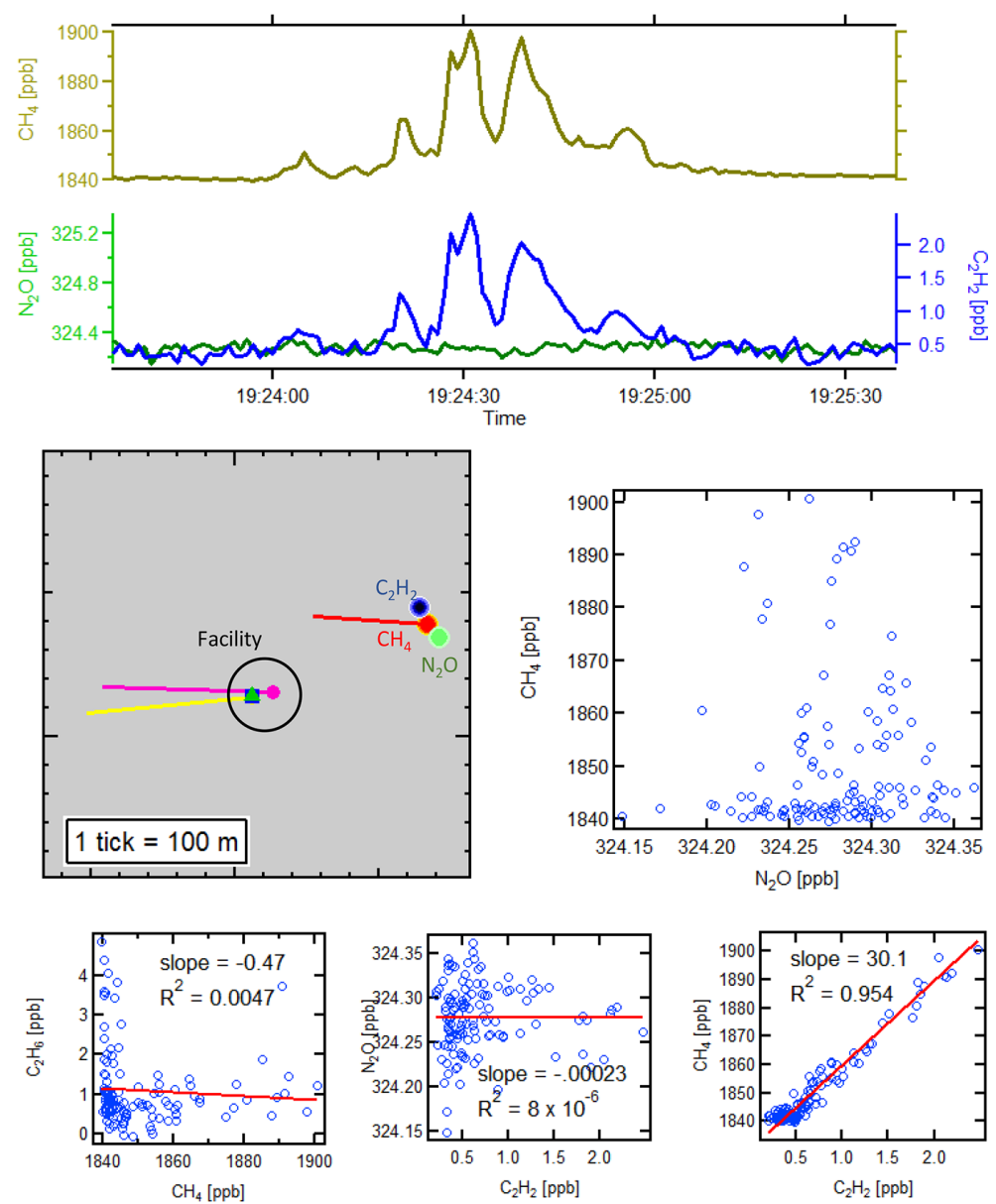

Figure 4. Example of a single-correlation plume $\left(\mathrm{CH}_{4}\right.$ correlation with $\left.\mathrm{C}_{2} \mathrm{H}_{2}\right)$. Top panel: time trace of $\mathrm{CH}_{4}, \mathrm{C}_{2} \mathrm{H}_{6}, \mathrm{~N}_{2} \mathrm{O}$, and $\mathrm{C}_{2} \mathrm{H}_{2}$ concentrations, showing high temporal correlation. Center left panel: map of tracer location (right side) and transect location (left side) during the course of the plume. Red, blue, and green weighted lines correspond to $\mathrm{CH}_{4}, \mathrm{C}_{2} \mathrm{H}_{2}$, and $\mathrm{N}_{2} \mathrm{O}$ intensities during the transect, spatially offset for clarity. Thin lines point into the wind at the mobile laboratory (red) and at the facility (light blue, pink, and yellow). Blue

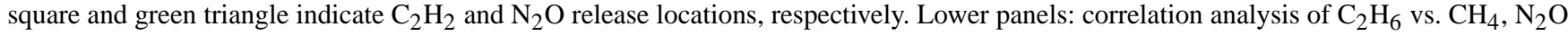
vs. $\mathrm{C}_{2} \mathrm{H}_{2}, \mathrm{CH}_{4}$ vs. $\mathrm{C}_{2} \mathrm{H}_{2}$, and $\mathrm{CH}_{4}$ vs. $\mathrm{N}_{2} \mathrm{O}$. The emission rate determined for this plume was found to be $8.1 \mathrm{SCFM}$.

yields variances for each plume type, the inverses of which are used as weighting factors for determining the weightedaverage FLER. Not surprisingly, the dual-correlation method exhibits the lowest variance of all plume types and is therefore the most preferred. This is likely due to the fact that these plumes correspond to a limit where full co-dispersion of the tracers has been achieved, i.e., both tracer plumes are experiencing the same local turbulence by the time they are measured by the mobile laboratory. In addition, no baseline subtraction is required in the dual-correlation method, which can be a source of uncertainty depending upon the signal-tonoise exhibited by the plume. The larger variance of the dualarea method is likely derived from the lack of co-dispersion of the tracers. In these scenarios, one tracer concentration may be enhanced relative to the other due to the fact that each tracer plume is experiencing different local turbulence en route to the mobile laboratory.
In the case of single-correlation plumes, the observed variance is found to be relatively small when the downwind tracer ratio (determined using integrated areas) is within a factor of 1.5 of the tracer flow rates (variance of $0.09 \mathrm{in} \mathrm{Ta-}$ ble 2). Because this variance is less than that for dual area (0.09 vs. 0.14$)$, single-correlation analysis is preferred over dual-area analysis for these plumes. Notably, the variance increases significantly from 0.09 to 0.22 when including all single-correlation plumes (i.e., with no tracer ratio filter). When the tracer ratio is more than a factor of 1.5 different than the tracer flow rates, the dual-area method is then preferred over single-correlation analysis. This indicates that although the both tracers are not being used to determine the FLER associated with that plume, filtering by their ratio can still yield more precise results. The decision tree employed during the analysis of this data set is presented in the Supplement. 
Table 2. Plume analysis types, preference, criteria, prevalence, and variance.

\begin{tabular}{|c|c|c|c|c|}
\hline Analysis type & Preference & Criteria & $\begin{array}{l}\text { \# of } \\
\text { plumes }\end{array}$ & $\begin{array}{l}\text { Variance } \\
(\sqrt{\text { variance }})\end{array}$ \\
\hline Dual correlation & 1 & $\begin{array}{l}\text { - } R^{2}>0.75: \mathrm{N}_{2} \mathrm{O} \text { vs. } \mathrm{C}_{2} \mathrm{H}_{2}, \mathrm{~N}_{2} \mathrm{O} \text { vs. } \mathrm{CH}_{4}, \\
\mathrm{C}_{2} \mathrm{H}_{2} \text { vs. } \mathrm{CH}_{4}, \mathrm{C}_{2} \mathrm{H}_{6} \text { vs. } \mathrm{CH}_{4} \\
\text { - Tracer ratio error }<1.5 \\
\text { - E / M ratio error }<1.5\end{array}$ & 250 & $0.04(0.2)$ \\
\hline Dual area & $2 / 3$ & $\begin{array}{l}-R^{2}>0.75: \mathrm{C}_{2} \mathrm{H}_{6} \text { vs. } \mathrm{CH}_{4} \\
\text { - Tracer ratio error }<2 \\
\text { - E / M ratio error }<1.5\end{array}$ & 441 & $0.14(0.37)$ \\
\hline Single correlation & $3 / 2$ & $\begin{array}{l}\text { - } R^{2}>0.75: \mathrm{C}_{2} \mathrm{H}_{6} \text { vs. } \mathrm{CH}_{4} \\
\text { Tracer vs. } \mathrm{CH}_{4} \\
\text { - E / M ratio error < } 1.5\end{array}$ & 728 & $\begin{array}{l}0.09 / 0.22 \\
(0.3 / 0.47)\end{array}$ \\
\hline Linear combination & 4 & $-R^{2}>0.75: \mathrm{C}_{2} \mathrm{H}_{6}$ vs. $\mathrm{CH}_{4}$ & 16 & - \\
\hline
\end{tabular}

\subsection{Ethane-to-methane ratio}

Finally, the ratio of ethane to methane in the measured downwind plume can also serve as an acceptance criterion regardless of plume classification. The amount of ethane in a natural gas mixture can vary from well to well and from one gathering facility to another (Kidnay et al., 2011). As such, the ethane content represents a unique "fingerprint" of a facility, providing a means to identify whether the $\mathrm{CH}_{4}$ measured in a plume is coming from the facility of interest. In this study, the ethane-to-methane ratio ( $\mathrm{E} / \mathrm{M}$ ratio) associated with a given facility was determined in one of two ways: from partner company GC analysis of the inlet/outlet gas or from $\mathrm{C}_{2} \mathrm{H}_{6}$ vs. $\mathrm{CH}_{4}$ correlation analysis of plumes when the mobile laboratory was on-site (and thus only observing emissions from the facility). While GC analysis data are preferred since they provide a completely independent (and external) check of the methodology, they were not always available on the date of the measurement. When possible, observed E / M ratios of plumes obtained when the mobile laboratory was on-site were compared to the GC data to confirm (or disprove) that the emission composition was in agreement with the GC data.

Both mobile laboratories measured ethane and methane at a $1 \mathrm{~Hz}$ sampling rate or faster, allowing for an accurate determination of the $\mathrm{E} / \mathrm{M}$ ratio of individual plumes. The $\mathrm{E} / \mathrm{M}$ ratio for every downwind plume obtained in the campaign (determined using correlation analysis) was measured and compared to the known ratio from GC analysis (or measured on-site $\mathrm{E} / \mathrm{M}$ ratio in cases where the $\mathrm{GC}$ data were unreliable). A detailed comparison between the observed E / M ratio and that from the inlet GC analysis is presented in the results section. A plume was only accepted for further analysis when the observed ratio was within a factor of 1.5 of the known value. This criterion was suspended in cases where the facility itself was actively changing the ethane content (e.g., from a demethanizer), where the E / M ratio was varying across the facility, or when the downwind $\mathrm{C}_{2} \mathrm{H}_{6}$ mixing ratio was below the detection sensitivity limit.

Finally, under certain scenarios, a small number of plumes that would be rejected as described above are manually accepted during analysis. These exceptions are possible for one of several reasons. One is that the plume transect is far enough downwind that the tracer or $\mathrm{CH}_{4}$ plume concentrations are near the detection limit of the onboard instruments. Under such a scenario the correlation analysis may reveal $R^{2}<0.75$ despite the plume being legitimate. Another possible reason for manually accepting a plume is when the $\mathrm{E} / \mathrm{M}$ ratio is variable across the facility, which is frequently due to the presence of a high emission point source such as a venting condensate tank. Because condensate tank emissions may exhibit an E / $\mathrm{M}$ ratio larger than that of the remainder of the facility, the observed downwind ratio may be variable, even on the timescale of a single plume.

\section{Results}

In this section, we present results from a number of case studies that illustrate the capabilities of the dual-tracer release method.

\subsection{Gathering facilities}

A gathering station serves as a point where multiple natural gas sources (wells) are combined to produce a high- 

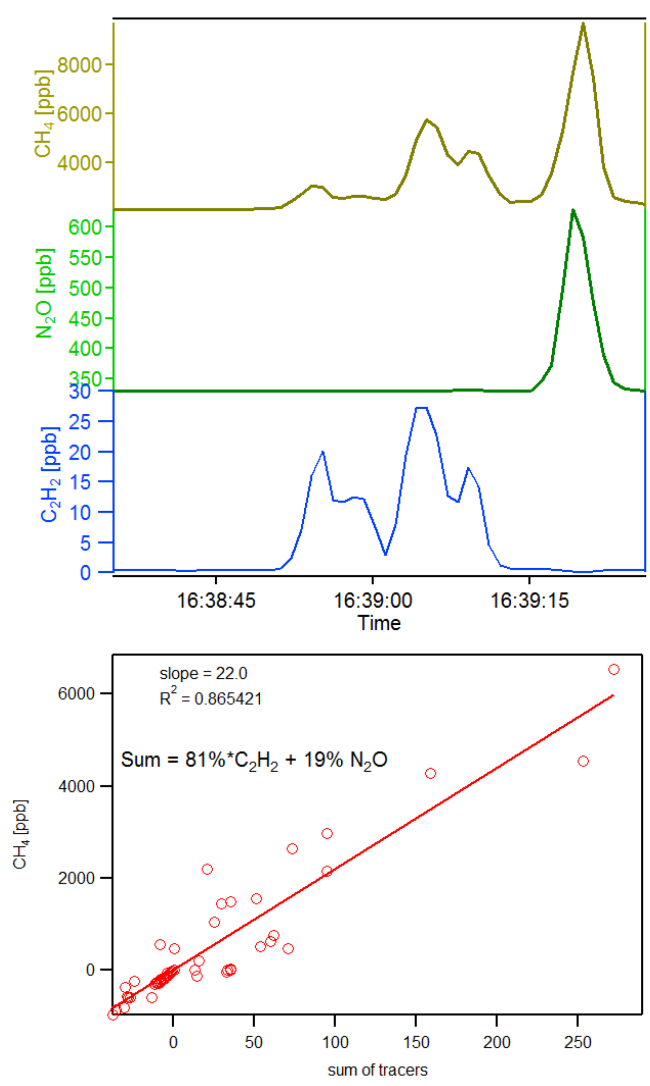

Figure 5. Example of analysis using a linear combination of tracer plumes. Note that $\mathrm{N}_{2} \mathrm{O}$ and $\mathrm{C}_{2} \mathrm{H}_{2}$ are associated with different sections of the $\mathrm{CH}_{4}$ plume (top). Adding the two tracer plumes in an $81 / 19 \%$ combination yields a correlation diagram (below) with high $R^{2}$ value (0.87). The emission rate determined from this plume is $56.1 \mathrm{SCFM}$.

pressure stream of gas. These facilities typically include equipment such as inlet separators to remove liquid phase water and condensate $\left(\mathrm{C}_{5+}\right)$, when present, and systems for pipeline maintenance activities (e.g., "pigging"). Compression at these facilities is accomplished by a series of 1 to 20 individual compressors powered by electric motors, reciprocating engines, or gas turbines with total engine powers ranging from 500 to $25000 \mathrm{HP}$ depending on the inlet gas pressure and total gas throughput (Mitchell et al., 2015). Gathering stations also typically contain condensate storage tanks, produced water storage tanks, and other gas handling equipment including pneumatic valves (often powered by natural gas) and gas metering systems. If the gas has a high water content, glycol dehydration systems are also frequently present to dry the gas (Goetz et al., 2014; Kidnay et al., 2011).

There are three main sources of continuous emissions from these facilities. First, compressors can serve as significant sources of $\mathrm{CH}_{4}$ via both fugitive leaks as well as through seals in the compressor housing. In the case of wet compressor seals, it should be noted that the primary emission route is due to absorption of methane into the seal fluid at high pressure, followed by exposure of the fluid to ambient pressure, where the methane is routed through a vent to atmosphere (EPA, 2006). Second, because the natural gas is typically under high pressure, fugitive and vented emissions may occur at the facility, including from continuous-bleed natural gas pneumatic devices, dehydration units, and a variety of flanges and valves. Third, methane slip (i.e., unburned methane in engine exhaust gases) through on-site combustion sources such as engines and turbines can be a source of $\mathrm{CH}_{4}$, depending upon a wide variety of combustion characteristics. The relative importance of this emission source to the FLER is discussed in the associated Measurements report (Mitchell et al., 2015) and in previous studies of combustion emissions in natural gas transmission and storage (Subramanian et al., 2014). Similarly, methane and other unburned hydrocarbons are present in flare emissions and may vary greatly depending upon the flare combustion efficiency (Torres et al., 2012).

Some intermittent methane emission sources may also be found at gathering facilities, such as intermittent-bleed natural gas-driven pneumatic controllers, produced water tanks, and condensate tanks. Of particular importance to the associated Measurements paper (Mitchell et al., 2015), produced water and condensate tanks may transiently emit $\mathrm{CH}_{4}, \mathrm{C}_{2} \mathrm{H}_{6}$, and higher hydrocarbons from thief hatches or other pressure relief valves attached to the tank. Because of the nature of the liquids stored in them, i.e., long-chain hydrocarbons, the ethane-to-methane ratio observed from a condensate tank can be much higher than the natural gas composition entering or exiting the facility. However, these units may sometimes also serve as venting release points for equipment on-site, in which case the $\mathrm{E} / \mathrm{M}$ ratio will be very similar to that of the inlet stream.

An example of an emission rate measurement from a compressor station (C station) is shown in Fig. 6a. Similar to the example plume shown in Fig. 2, this plume as accepted as dual correlation $\left(R^{2}=0.998\right.$, tracer ratio error $=1.05, \mathrm{E} / \mathrm{M}$ ratio error $=1.4$ ). The average emission rate from this facility was found to be $43.8 \pm 8.4 \mathrm{~kg} \mathrm{~h}^{-1}$. In this case, the methane and ethane signals are strongly correlated with both tracers at a distance of $1600 \mathrm{~m}$ downwind of the facility. Note that inclusion of the $\mathrm{CO}$ and $\mathrm{CO}_{2}$ in the analysis indicates that both of these gases are also being emitted from the facility, likely due to combustion. While this plume alone can provide an accurate determination of the FLER from the facility, even more information can be extracted by also investigating transects from only $100 \mathrm{~m}$ away, shown in Fig. $6 \mathrm{~b}$ (a dual-area plume, with tracer ratio error $=0.7, \mathrm{E} / \mathrm{M}$ ratio error $=1.5)$. While such a close transect may not provide as precise a FLER, we see from the figure that the $\mathrm{CO}$ and $\mathrm{CO}_{2}$ signatures are coincident with only a fraction of the methane being emitted and are not well correlated with it. This indicates that some, but not all, $\mathrm{CH}_{4}$ emitted at the facility may be associated with combustion. In this case, the remaining $\mathrm{CH}_{4}$ emission is likely from other non-combustion sources 

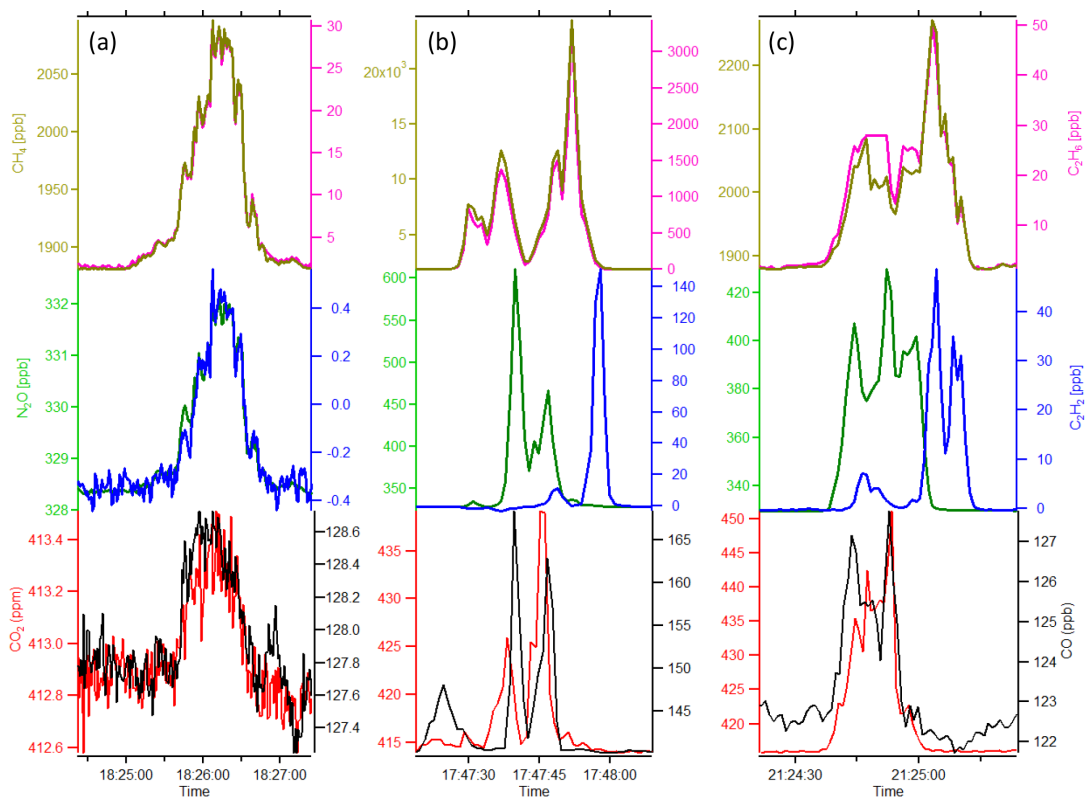

Figure 6. Three exemplary plumes from a gathering station: (a) far-field plume $(1.6 \mathrm{~km})$ showing strong correlation between $\mathrm{CH}_{4}$, $\mathrm{C}_{2} \mathrm{H}_{6}$, $\mathrm{N}_{2} \mathrm{O}, \mathrm{C}_{2} \mathrm{H}_{2}, \mathrm{CO}_{2}$, and $\mathrm{CO}$; (b) close plume transect (100 m away) of same facility, showing loss of correlation and isolation of $\mathrm{CO}_{2}$ and $\mathrm{CO}$ combustion products to a section of the facility; (c) example of a close plume transect (200 $\mathrm{m}$ away) showing $\mathrm{CO}_{\text {and }} \mathrm{CO}_{2}$ correlation with a component of the $\mathrm{CH}_{4}$ trace.

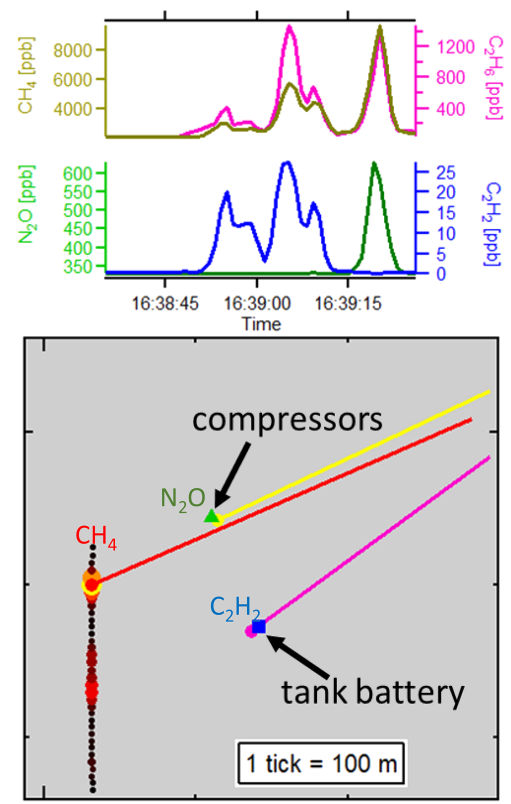

Figure 7. Example of varying E / M ratio during a close transect due to the presence of a condensate tank battery on-site. Note the $\sim 2 \times$ decrease in the $\mathrm{E} / \mathrm{M}$ ratio toward the end of the plume.

on-site. At some facilities, such as that shown in Fig. 6c, CO and $\mathrm{CO}_{2}$ are correlated with a distinct part of the $\mathrm{CH}_{4}$ plume, indicating the presence of a combustion source that is emitting $\mathrm{CH}_{4}$ or co-located with one that is and clearly associated with one section of the facility. Because the goals of the G\&P study are to understand both overall emissions and their origins, this type of analysis can aid in understanding the relative role of combustion sources and methane slip in G\&P $\mathrm{CH}_{4}$ emissions. In the case of the compressor station associated with the plume in Fig. $6 \mathrm{c}$, the area of the facility with $\mathrm{CO}, \mathrm{CO}_{2}$, and $\mathrm{CH}_{4}$ emissions is the compressor/engine section, while the area with no $\mathrm{CO} / \mathrm{CO}_{2}$ corresponds to other non-combustion sources on-site. Thus, Fig. 6 illustrates the important role that the auxiliary gas measurements (in this case $\mathrm{CO}$ and/or $\mathrm{CO}_{2}$ ) can play in identifying sources of emissions.

Because they are ubiquitous at both production and gathering facilities, it is of interest to this study to understand, and quantify when possible, what fraction of emitted methane is coming from condensate and produced water tanks. Shown in Fig. 7 is an example of the emission profile observed at a compressor facility containing a condensate tank, illustrating another example of the utility of close $(<200 \mathrm{~m})$ transects. In this case, one tracer $\left(\mathrm{N}_{2} \mathrm{O}\right)$ was placed next to the compressors, while another $\left(\mathrm{C}_{2} \mathrm{H}_{2}\right)$ was placed near a battery of three condensate tanks. As shown in the transect trace, both of these sources (compressors and tanks) are correlated with their respective tracers but have very different $\mathrm{E} / \mathrm{M}$ ratios. Here the relative intensities of the $\mathrm{CH}_{4}$ plumes associated with the different $\mathrm{E} / \mathrm{M}$ ratios indicate comparable emission rates between the two sources. As discussed in the associated Measurements paper (Mitchell et al., 2015), the sub-facility spatial resolution afforded by tracer release, along with the 
measurement of auxiliary species such as ethane, provides the ability to address the contributions of particular equipment, especially condensate tanks, to emissions from G\&P facilities. Here, for example, analysis using a linear combination of tracers as described above reveals that the $\mathrm{CH}_{4}$ emission from the condensate tank represents $50 \%$ of the overall $\mathrm{CH}_{4}$ emission rate from the facility. The average total emission rate from this facility was found to be $48 \pm 22 \mathrm{~kg} \mathrm{~h}^{-1}$.

While not always the case, it is common to find a larger ethane content in emissions from condensate tanks relative to the inlet gas composition due to the larger fraction of ethane in the condensate itself. It should be noted that daily temperature variations (producing "breathing" emissions) may change the relative vapor pressures of ethane and methane in the condensate tank, and the filling/emptying schedule of the condensate tank (producing "working" emissions) may alter condensate composition. Both of these activities can therefore change the $\mathrm{E} / \mathrm{M}$ ratio of the tank emissions over the course of the day.

\subsection{Amine treatment}

The composition of natural gas often depends upon its geologic origin (or play). To illustrate this effect, we compare emissions from facilities associated with different gas sources: shale and coal bed methane (Whiticar, 1994; Kidnay et al., 2011). Shale gas, tight gas, and conventional gas contain varying amounts of ethane and higher hydrocarbons, typically with low levels of $\mathrm{CO}_{2}$. Coal bed methane, however, typically contains little ethane and up to $40 \% \mathrm{CO}_{2}$ (Kidnay et al., 2011). This carbon dioxide is particularly interesting since in this case it is not an indicator of combustion. Other combustion sources within the facility can be distinguished by the presence of $\mathrm{CO}$.

If $\mathrm{CO}_{2}$ is present in high amounts (>3\%), it must be removed from the natural gas prior to transmission and storage. It can be removed from a gas stream by passing the natural gas through a vapor of monoethanolamine or other related amine compounds. This process is called "amine treatment" or "amine scrubbing" (Kidnay et al., 2011; Rochelle, 2009; Bottoms, 1930). The amine binds to the $\mathrm{CO}_{2}$ and is then regenerated through heating. $\mathrm{CO}_{2}$ is thus evolved from this process, so the facility's $\mathrm{CO}_{2}$ emissions relative to $\mathrm{CH}_{4}$ will be higher than would be expected for a direct leak of the untreated gas. Heating is applied through combustion of excess fuel (natural gas or other easily available source) so $\mathrm{CO}_{2}$ may sometimes be present along with small amounts of combustion products such as $\mathrm{CO}$ and $\mathrm{NO}_{x}$. Amine treatment is also used for the removal of hydrogen sulfide $\left(\mathrm{H}_{2} \mathrm{~S}\right)$, with the main difference being that the $\mathrm{H}_{2} \mathrm{~S}$ is highly toxic and must be captured or combusted.

Figure 8 contrasts emissions from facilities associated with coal bed methane and shale gas. The facility in Fig. $8 \mathrm{a}$ is a coal bed methane treatment plant without compression. The average emission rate from this facility was $142 \pm 50 \mathrm{~kg} \mathrm{~h}^{-1}$.
The compressor/dehydration facility shown in Fig. $8 \mathrm{~b}$ (the same compressor facility discussed above) had four compressors and is in a shale region with characteristically high ethane content in the gas. The ethane content of the coal bed methane is observed at a molar ratio $\mathrm{C}_{2} \mathrm{H}_{6} / \mathrm{CH}_{4}=0.0215$ (Fig. 8a), while the shale-gas facility emissions have a much higher measured ratio, $\mathrm{C}_{2} \mathrm{H}_{6} / \mathrm{CH}_{4}=0.164$ (Fig. 8b). The $\mathrm{CO}_{2}$ emissions vary even more greatly between the facilities, at $\mathrm{CO}_{2} / \mathrm{CH}_{4}=165$ vs. $\mathrm{CO}_{2} / \mathrm{CH}_{4}=3.3$. The molar ratio of $\mathrm{CO}_{2}$ to $\mathrm{CH}_{4}$ in the former facility's emissions $\left(\mathrm{CO}_{2} / \mathrm{CH}_{4}=165\right)$ is 4 orders of magnitude higher than the operator data for the inlet gas $\left(\mathrm{CO}_{2} / \mathrm{CH}_{4}=0.106\right)$. For Fig. 8a, at the distances sampled no other significant combustion products (such as $\mathrm{CO}$ ) were observed, indicating that the primary source of $\mathrm{CO}_{2}$ is the amine treatment process. This information, along with the observed high degree of correlation between $\mathrm{CO}_{2}$ and $\mathrm{CH}_{4}$ at intermediate distances $(\sim 500 \mathrm{~m})$, suggests that the primary $\mathrm{CH}_{4}$ emission source is located within or near the amine treatment area of the facility.

\subsection{Natural gas processing}

Natural gas processing plants are large, complex facilities that remove unwanted compounds in the incoming gas stock (e.g., $\mathrm{H}_{2} \mathrm{~S}, \mathrm{CO}_{2}, \mathrm{H}_{2} \mathrm{O}$ ) and separate other high-value compounds (i.e., natural gas liquids, as discussed below) from the gas to produce pipeline-quality natural gas. Physically, processing plants often serve as the nexus between the gathering networks in the area and a transmission system working to serve longer-range transport. They are typically characterized by capacity throughputs of 3-1500 million standard cubic feet per day (MMscfd; equivalent to 2400$1200000 \mathrm{~kg} \mathrm{~h}^{-1}$ ). The types of equipment and the processes that are undertaken at a gas-processing plant depend on the composition of the gas in the region. Many plants utilize multiple processing "trains" to enable flexible operation. The equipment and steps in each train can vary depending again on the region and the engineering decisions made by the operator of the plant (Kidnay et al., 2011). It should also be noted that not all natural gas in the US supply chain is processed. Rather, in cases where natural gas composition does not contain substantial levels of natural gas liquids or $\mathrm{H}_{2} \mathrm{~S} / \mathrm{CO}_{2}$ (i.e., is dry and sweet), the natural gas flows directly from gathering facilities into transmission pipelines (and sometimes directly into distribution networks).

The initial process that is typically found at a gasprocessing plant involves a continuation of the treatment types found in the gathering system of the region. At some facilities, the initial product will be a first cut at collecting natural gas condensate, which is typically comprised of functionalized hydrocarbons above $\mathrm{C}_{5}$, using an inlet separator (when they have not been collected further upstream in the gathering network). Water may also be removed using glycol dehydration. Other trace contaminants are often filtered using a series of molecular sieve apparatus that are staggered for 
(a)
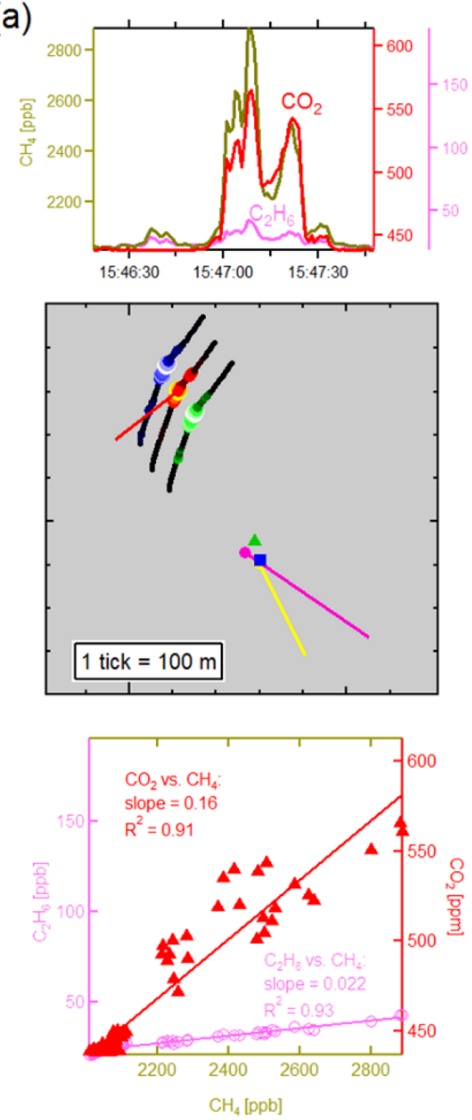

(b)
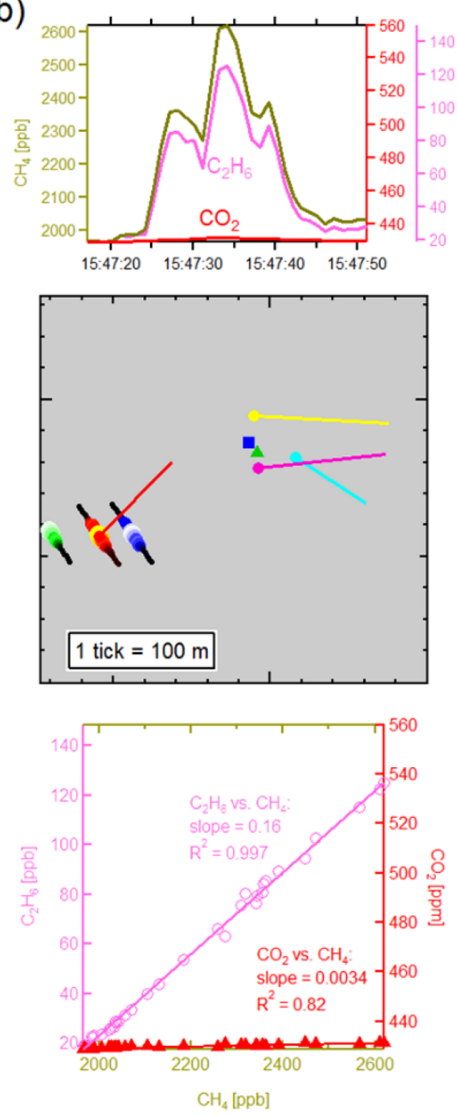

Figure 8. Example of differing $\mathrm{CO}_{2}$ plume profiles as a function of gas play: (a) emissions from a plant in a coal-gas region, with an amine scrubbing unit, showing significant $\mathrm{CO}_{2}$ emissions; and (b) emissions from a gathering facility with no treatment in a shale-gas region.

effective continuous regeneration. As discussed below, natural gas liquids are removed from the gas stream using either a cryogenic separation or separation based on solubility in lean oil (Kidnay et al., 2011). Additional details of this class of compounds and specific equipment used are discussed in the next section.

Due to the nature of the various processing steps and types of equipment found at processing plants, as well as the somewhat larger geographic scale they typically occupy, there are typically multiple methane emission points with various coemitted compounds. On the surface, this type of source is a direct challenge to the tracer release methodology given the constraint for the controlled tracer release to be as close to the emission source as possible. The following examples and discussion describe how these types of facility are quantified using the dual-tracer methodology as well as using the nature of the co-emitted compounds to deduce the dominant emission sources.

The geographic scale of processing plants presents a challenge to the dual-tracer flux ratio quantification given the constraints of wind direction and roadway access. Figure 9 depicts a pair of transects from a processing plant. The average emission rate measured at this plant was found to be
$128 \pm 66 \mathrm{~kg} \mathrm{~h}^{-1}$. Each transect was collected with the mobile lab maneuvering from north to south. This is depicted by the rainbow bar in each of the two split time series (a) and (b) in the left hand panel and portrayed on the right-hand panel with the relative distance (north vs. east). In the case where the transect was captured at the facility fence line (a), we see relatively high spikes in plume mixing ratios with three different quantifiable $\mathrm{E} / \mathrm{M}$ ratios. Note that the tracer release locations were relatively close to one another and this is reflected in the spatial coherence in both of the transects.

In the case of the more distant $(\sim 1.2 \mathrm{~km})$ transect, the mixing ratios of ethane and methane are significantly less spiked. Careful analysis of the time and space dependence of the $\mathrm{E} / \mathrm{M}$ ratio suggests that even at this distance the ratio in the northern sector of the facility is different than that in middle and southern sections. This observation is corroborated anecdotally by the physical location of the liquids storage and natural gas transmission hardware on-site. In this facility the recompression of pipeline-grade natural gas takes place in the southern third of the facility. This corresponds to the lowest $\mathrm{E} / \mathrm{M}$ ratio (red-purple in the time series) but is a significant source of $\mathrm{CH}_{4}$ emissions $(\sim 50 \%)$ from the facility. The liquids storage and handling takes place at the northern 

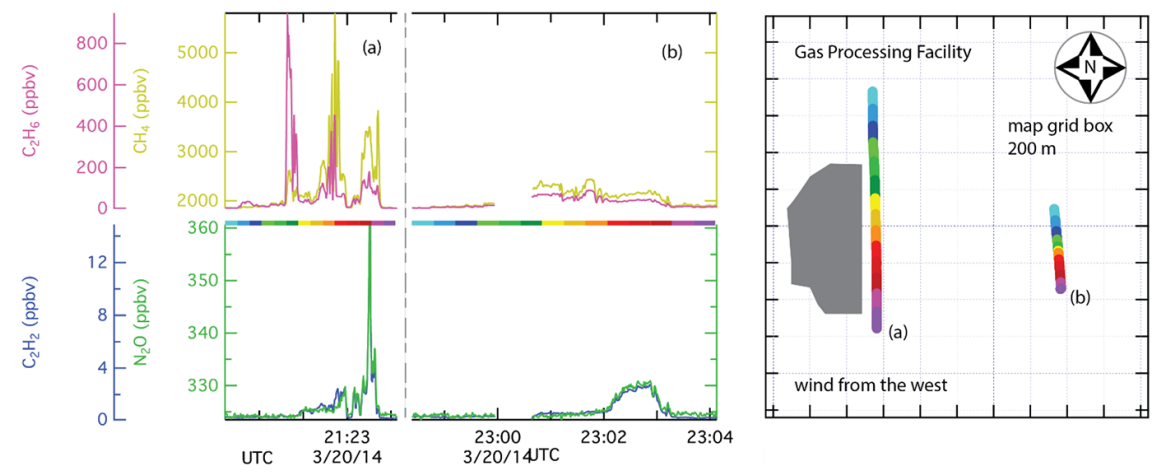

Figure 9. In the left-hand panel, the time series for methane, ethane, nitrous oxide, and acetylene are depicted for two transects, (a) and (b). In the right-hand panel, the geographic location is portrayed for the processing plant (grey) and the two transects (a) and (b). See text for additional discussion.

section of the facility. The effective leak rate of methane is less than in other sections of the facility because the methane is at residual levels in the liquids headspace. The $\mathrm{E} / \mathrm{M}$ ratio in the green and yellow section of the time series is greater because this is where the NGL stock is being processed.

To quantify the FLER from processing facilities, frequently the dual-area analysis method is used. In the case of the close transects, the measured methane emission rates often exhibit substantial variance. The average of multiple close transects typically was found to be comparable to values determined by more distant, better-mixed plume intercepts, when such a comparison was available.

\subsection{Natural gas liquids and condensates}

NGL is an umbrella term (EIA, 2013) for the many different chemicals and blends extracted in the liquid form from natural gas. Depending on the equipment available and the demand for the various products, the amount of processing of natural gas can vary greatly. At the lower end of the spectrum, the gas may undergo dehydration and just enough removal of $\mathrm{C}_{2+}$ to meet pipeline specifications, such that no liquids condense at pipeline pressures. Removal of other impurities such as $\mathrm{CO}_{2}$ and $\mathrm{H}_{2} \mathrm{~S}$ may also be required to meet pipeline specifications. At the highest end of the processing spectrum, cryogenic distillation will be employed to sequentially extract methane (demethanizer), ethane (deethanizer), propane, iso- and n-butane, and higher hydrocarbons. This processing can occur at a single facility or can be performed in several steps between different facilities. The net result is to separate the methane (and/or ethane) from other condensable compounds that may still be present in the feed stock after the various upstream treatments. The liquid product at this stage is referred to as " $x$ " or " $y$ " grade liquid depending on the cut temperature and ethane content in the liquid. In some of the processing plants in this study, this liquid stream is stored in this state and shipped off-site via an NGL pipeline or tanker truck. In other facilities studied, the liquid is further fractionated, sequentially removing ethane, then propane, then butane (Kidnay et al., 2011). Because of the low methane content within the liquid, this further processing of the NGL is not expected to significantly contribute to the FLER but may play a role in the E / M ratio that is observed downwind.

Many of the facilities visited in this study were in so-called "ethane rejection" mode, meaning that distillation towers were operated at lower liquids recovery levels and purified ethane is treated as a byproduct of the $\mathrm{C}_{3+}$ extraction. As a byproduct, it frequently was re-injected into the natural gas stream. This occurs when there is less demand for purified ethane as a feedstock for ethylene, a process that occurs at an extremely limited number of locations in the US.

As in the case of identifying condensate tank emissions, the $\mathrm{E} / \mathrm{M}$ ratio can inform the attribution of a methane emission source to individual pieces of NGL equipment. A striking example is shown in Fig. 10. This facility has two compressors, dehydrators, condensate tanks, and processing equipment. The measured $\mathrm{CH}_{4}$ emission rate from this facility is $58 \pm 22 \mathrm{~kg} \mathrm{~h}^{-1}$. The nitrous oxide tracer (green marker) was placed near the condensate tanks and the acetylene tracer (blue marker) near the compressors. Northeast of the acetylene tracer, above-ground piping marks the facility's inlet and outlet (natural gas) as well as a liquids pipeline carrying a mixture of ethane and propane produced at the facility. The $\mathrm{E} / \mathrm{M}$ ratio for the mixed facility plume was 0.0576 , while the ratio for the liquids pipeline and inlet/outlet region was 14.58 , i.e., nearly entirely ethane. Therefore, this transect indicates that the pipeline is not a significant source of $\mathrm{CH}_{4}$ emissions.

\subsection{Comparison of $\mathrm{C}_{2}$ content with operator data}

In this study, the $\mathrm{E} / \mathrm{M}$ ratio serves several purposes: (i) confirmation that a plume is from a target facility, (ii) elimination of plumes from neighboring facilities or biogenic sources, and (iii) distinguishing between different emission sources within a given facility. The quantification of a facility's methane emissions leverages (i) and (ii) above. Fig- 
Table 3. Measured E / M ratios as a function of gas type at gathering and processing facilities. Minimum, median, and maximum average measured ratios are noted. Offshore gas is not included here due to the small number of offshore facilities measured.

\begin{tabular}{lrrrr}
\hline Gas type & \multicolumn{2}{c}{ Measured E / M ratio } & & \\
& $\min$ & median & $\max$ & count \\
\hline Coal bed methane & 0.00 & 0.014 & 0.045 & 8 \\
Coal bed methane & 0.0057 & 0.018 & 0.031 & 4 \\
and conventional & & & & \\
Shale & 0.0055 & 0.051 & 0.24 & 64 \\
Conventional & 0.012 & 0.068 & 0.22 & 37 \\
\hline
\end{tabular}
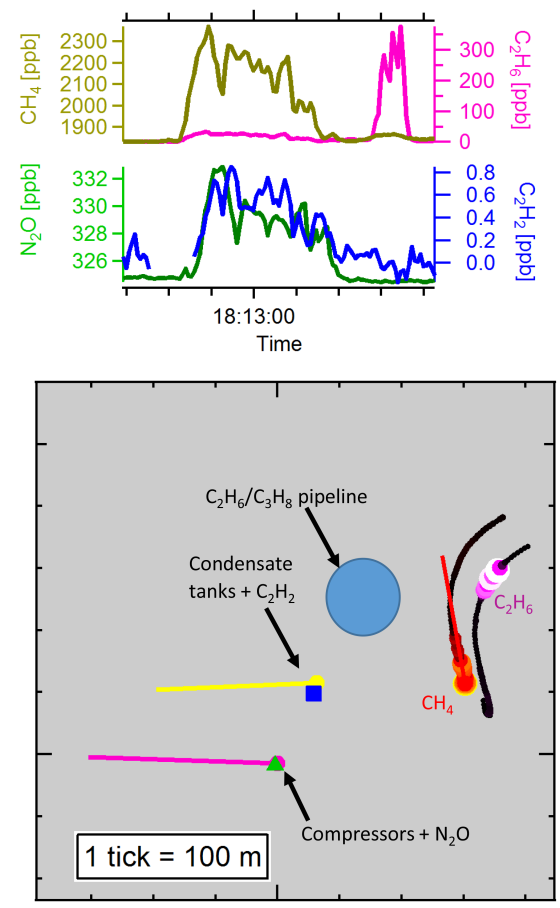

Figure 10. Downwind plume transect showing mixing ratio as a function of time (top) and a map (bottom). Tracer release locations are shown as a green triangle (nitrous oxide) and a blue square (acetylene). The plume transect is colored by methane mixing ratio (black to yellow). Ethane mixing ratio is also shown with a geographic offset. Wind vectors (pink, red, and yellow) point into the wind.

ure 11 shows a comparison between the measured E / M ratios at each facility and the operator-provided data on gas composition. Agreement is good overall, with a few outliers. Also shown in the figure are $95 \%$ confidence limits on the measured $\mathrm{E} / \mathrm{M}$ ratios. Large error bars in the facility average for $\mathrm{E} / \mathrm{M}$ ratios are usually due to variations in the emission composition, since the error for any individual ratio measurement is low. The operator gas composition information was not always measured on the same day as the field testing. For gathering facilities, gas composition is periodically measured by gas sampling and subsequent third-party analysis.

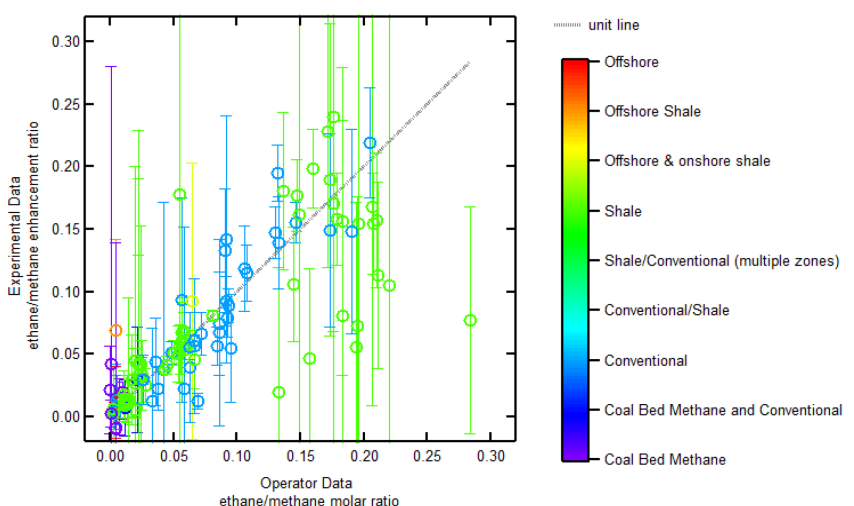

Figure 11. Comparison between measured ethane/methane ratio and operator data on gas composition. Error bars correspond to the $95 \%$ confidence limits from the replicate experimental plumes. Points are also colored by the type of gas at each site. A line to guide the eye is drawn at a $1: 1$ correspondence between measured and operator data.

For processing plants, gas composition data are typically acquired in real time at multiple locations at the facility. In either case, the gas composition exiting the gathering facility or processing plant may not always reflect the gas composition of the emission sources. This can be due to the $\mathrm{E} / \mathrm{M}$ ratio changing as the gas moves through the facility or from emissions from condensate/produced water tanks. This variety of equipment and processes at gathering facilities and processing plants explains much of the discrepancy between measured and operator $\mathrm{E} / \mathrm{M}$ ratios compared to the transmission and storage study, where the composition of the gas does not vary during handling (Subramanian et al., 2014; Yacovitch et al., 2014). Table 3 outlines the minimum, median, and maximum facility average $\mathrm{E} / \mathrm{M}$ ratios divided by primary gas type. It should be noted that the classification by gas type is not rigid. That is, there may be multiple gas types other than the primary present at these facilities. The points in Fig. 11 are colored based on this gas classification. As noted above, coal bed methane facilities typically have the lowest E / M ratios. Conventional facilities sit somewhere in the middle, with the shale-gas facilities split into several clusters. The shale gas is scattered about the plot, with some clustering associated with various geographic basins. The three main shale clusters observed in Fig. 11 (green points) correspond loosely to: the Denver (Denver-Julesburg), Permian (Eagle Ford and Delaware), and Appalachian basins ( 12-23\%); the Anadarko (Mississippian Lime gas play), Uinta (Natural Buttes), and Piceance basins ( 4-6\%); and the Arkoma basin $(\sim 1 \%)$. Other shale basins were also visited but the number of facilities for each of these basins is low.

\section{Conclusions}

Reported here is a detailed description of the measurement and analysis methods used during a field campaign to quan- 
tify methane emissions and emission sources from natural gas gathering and processing facilities. The campaign covered a wide range of geographic regions, basins, gas types, and facilities. The measurement method used, the dual-tracer ratio, yielded facility-specific methane emission rates for 130 facilities. The field measurements were complemented by on-site infrared imaging and equipment surveys. The analysis technique applied to the data allowed for accurate determination of the emission rates using multiple downwind plume categories. Overall emission profiles, quantified by measuring $\mathrm{CH}_{4}, \mathrm{C}_{2} \mathrm{H}_{6}, \mathrm{CO}, \mathrm{CO}_{2}, \mathrm{C}_{2} \mathrm{H}_{2}$, and $\mathrm{N}_{2} \mathrm{O}$, frequently afforded an understanding of the unique chemical signatures associated with various natural gas gathering and processing equipment on-site. This paper provides a background and method description for additional work aimed at compiling the data set (Mitchell et al., 2015) and developing an estimate (with uncertainty) for the total methane emissions from gathering and processing in the US (Marchese et al., 2015).

\section{The Supplement related to this article is available online at doi:10.5194/amt-8-2017-2015-supplement.}

Acknowledgements. This work was funded by the Environmental Defense Fund (EDF), as well as Access Midstream, Anadarko Petroleum Corporation, Hess Corporation, Southwestern Energy, and Williams. These sponsors also provided important technical insight, facility data, and site access. Subsequent to the field sampling campaign of this study, the Williams company purchased the controlling interest in Access Midstream Partners L.P. ("Access") by acquiring $100 \%$ of the general partnership interest of Access. Funding for EDF's methane research series is provided by F. and S. Druckenmiller, Heising-Simons Foundation, B. and S. Oberndorf, B. and S. Reeves, Robertson Foundation, Alfred P. Sloan Foundation, TomKat Charitable Trust, and the Walton Family Foundation. Although not a financial sponsor, DCP Midstream provided technical insight and site access to a processing plant in the DJ Basin. Ramon Alvarez and Drew Nelson of EDF provided valuable technical and logistical support and guidance. We also acknowledge D. T. Allen, G. Heath, M. Levi, and J. McCarthy of the Science Advisory Panel for providing important advice, guidance, and input. The authors would like to thank J. Nowak, K. Lizardo, J. Curry, R. McGovern, M. Agnese, B. Brooks, X. Cabral, and K. Taylor for their contributions in the field during this project. Aerodyne Research, Inc. would also like to acknowledge critical instrument development support from the Department of Energy SBIR program under contract DE-SC0004578.

Edited by: G. Phillips

\section{References}

Allen, D. T., Torres, V. M., Thomas, J., Sullivan, D. W., Harrison, M., Hendler, A., Herndon, S. C., Kolb, C. E., Fraser, M. P., Hill, A. D., Lamb, B. K., Miskimins, J., Sawyer, R. F., and Seinfeld,
J. H.: Measurements of methane emissions at natural gas production sites in the United States, P. Natl. Acad. Sci. USA, 110, 17768-17773, 2013.

Beychok, M. R.: Fundamentals Of Stack Gas Dispersion, Newport Beach, CA, USA, 2005.

Bottoms, R. R.: Separating acid gases, US Patent 1783901, 1930.

Bullock, A. and Nettles, R.: Remote Sensing VOC Project, Texas Commission on Environmental Quality, Texas, USA, 2014.

Crosson, E. R.: A cavity ring-down analyzer for measuring atmospheric levels of methane, carbon dioxide, and water vapor, Appl. Phys. B-Lasers O., 92, 403-408, 2008.

Czepiel, P. M., Mosher, B., Harriss, R. C., Shorter, J. H., McManus, J. B., Kolb, C. E., Allwine, E., and Lamb, B. K.: Landfill methane emissions measured by enclosure and atmospheric tracer methods, J. Geophys. Res., 101, 16711-16719, 1996.

Draxler, R. R. and Hess, G. D.: Description of the HYSPLIT_4 modeling system, NOAA Air Resources Laboratory, Silver Spring, MDERL ARL-224, 24 pp., 1997.

Draxler, R. R. and Hess, G. D.: An Overview of the HYSPLIT_4 modeling system of trajectories, dispersion, and deposition, Aust. Meteorol. Mag., 47, 295-308, 1998.

EIA: Natural Gas Processing: The Crucial Link Between Natural Gas Production and Its Transportation to Market Energy Information Administration, 2006.

EIA: EIA's Proposed Definitions for Natural Gas Liquids, U.S. Energy Information Administration, Washington, DC, USA, 5 pp., 2013.

EPA: Replacing Wet Seals with Dry Seals in Centrifugal Compressors Natural Gas STAR Program, 2006.

EPA: National Greenhouse Gas Emissions Data, http://epa. gov/climatechange/ghgemissions/usinventoryreport.html (last access: August 2014), 2014a.

EPA: Annual Energy Outlook 2014 with projections to 2040, EPA Energy Information Administration, 2014b.

Goetz, J. D., Floerchinger, C. R., Fortner, E., Wormhoudt, J., Massoli, P., Knighton, W. B., Herndon, S. C., Kolb, C. E., Knipping, E. M., Shaw, S. L., and DeCarlo, P. F.: Atmospheric Emission Characterization of Marcellus Shale Natural Gas Development, Environ. Sci. Technol., in press, 2014.

Harrison, M. R., Galloway, K. E., Hendler, A., Shires, T. M., Allen, D. D., Foss, D. M., Thomas, J., and Spinhirne, J.: Natural Gas Industry Methane Emission Factor Improvement Study Final Report, Cooperative Agreement No. XA-83376101, 2011.

Herndon, S. C., Jayne, J. T., Zahniser, M. S., Worsnop, D. R., Knighton, B., Alwine, E., Lamb, B. K., Zavala, M., Nelson, D. D., McManus, J. B., Shorter, J. H., Canagaratna, M. R., Onasch, T. B., and Kolb, C. E.: Characterization of urban pollutant emission fluxes and ambient concentration distributions using a mobile laboratory with rapid response instrumentation, Faraday Discuss., 130, 327-339, 2005.

Jiménez, R., Herndon, S., Shorter, J. H., Nelson, D. D., McManus, J. B., and Zahniser, M. S.: Atmospheric trace gas measurements using a dual quantum-cascade laser mid-infrared absorption spectrometer, Proc. of SPIE, Novel In-Plane Semiconductor Lasers IV, 5738, 318, 2005.

Jumonville, J.: Tutorial on Cryogenic Turboexpanders, Proceedings of the 39th Turbomachinery Symposium, 2010.

Karion, A., Sweeney, C., Pétron, G., Frost, G., Michael Hardesty, R., Kofler, J., Miller, B. R., Newberger, T., Wolter, S., Banta, R., 
Brewer, A., Dlugokencky, E., Lang, P., Montzka, S. A., Schnell, R., Tans, P., Trainer, M., Zamora, R., and Conley, S.: Methane emissions estimate from airborne measurements over a western United States natural gas field, Geophys. Res. Lett., 40, 43934397, doi:10.1002/grl.50811, 2013.

Kidnay, A. J., Parrish, W. R., and McCartney, D. G.: Fundamentals of Natural Gas Processing, 2nd ed., CRC Press, 2011.

Lamb, B., Westberg, H., and Allwine, G.: Isoprene emission fluxes determined by an atmospheric tracer technique, Atmos Environ., 20, 1-8, 1986.

Lamb, B., McManus, J. B., Shorter, J. H., Kolb, C. E., Mosher, B., Harriss, R. C., Allwine, E., Blaha, D., Howard, T., Guenther, A., Lott, R. A., Siverson, R., Westberg, H., and Zimmerman, P.: Development of Atmospheric Tracer Methods to Measure Methane Emissions from Natural Gas Facilities and Urban Areas, Environ. Sci. Technol., 29, 1468-1479, 1995.

Lamb, B. K., Edburg, S. L., Ferrera, T. W., Howard, T., Harrison, M., Kolb, C. E., Townsend-Small, A., Dyck, W., Possolo, A., and Whetstone, J.: Direct Measurements Show Decreasing Methane Emissions from Natural Gas Local Distribution Systems in the United States, Environ. Sci. Technol., 49, 5161-5169, 2015.

Marchese, A. J., Vaughn, T. L., Zimmerle, D., Martinez, D., Williams, L., Robinson, A. L., Mitchell, A. L., Subramanian, R., Tkacik, D. S., Roscioli, J. R., and Herndon, S. C.: Methane emissions from United States natural gas gathering and processing, in preparation, 2015.

McManus, J. B., Nelson, D. D., Shorter, J. H., Jiminez, R., Herndon, S., Saleska, S., and Zahniser, M. S.: A high precision pulsed QCL spectrometer for measurements of stable isotopes of carbon dioxide, J. Mod. Optic, 52, 2309-2321, 2005.

Mitchell, A. L., Tkacik, D. S., Roscioli, J. R., Herndon, S. C., Yacovitch, T. I., Martinez, D. M., Vaughn, T. L., Sullivan, M., Floerchinger, C., Marchese, A., and Robinson, A. L.: Measurements of Methane Emissions from Natural Gas Gathering Facilities and Processing Plants: Measurement Results, Environ. Sci. Technol., 49, 3219-3227, 2015.

Mosher, B. W., Czepiel, P. M., Harriss, R. C., Shorter, J. H., Kolb, C. E., McManus, J. B., Allwine, E., and Lamb, B. K.: Methane Emissions at Nine Landfill Sites in the Northeastern United States, Environ. Sci. Technol., 33, 2088-2094, 1999.

Nehrkorn, T., Eluszkiewicz, J., Wofsy, S. C., Lin, J. C., Gerbig, C., Longo, M., and Freitas, S.: Coupled Weather Research and Forecasting-Stochastic Time-Inverted Lagrangian Transport (WRF-STILT) Model, Meteorol. Atmos. Phys., 107, 51-64, 2010.

Pétron, G., Frost, G., Miller, B. R., Hirsch, A. I., Montzka, S. A., Karion, A., Trainer, M., Sweeney, C., Andrews, A. E., Miller, L., Kofler, J., Bar-Ilan, A., Dlugokencky, E. J., Patrick, L., Moore Jr., C. T., Ryerson, T. B., Siso, C., Kolodzey, W., Lang, P. M., Conway, T., Novelli, P., Masarie, K., Hall, B., Guenther, D., Kitzis, D., Miller, J., Welsh, D., Wolfe, D., Neff, W., and Tans, P.: Hydrocarbon emissions characterization in the Colorado Front Range: A pilot study, J. Geophys. Res., 117, D04304, doi:10.1029/2011JD016360 2012a.

Pétron, G., Frost, G., Miller, B. R., Hirsch, A. I., Montzka, S. A., Karion, A., Trainer, M., Sweeney, C., Andrews, A. E., Miller, L., Kofler, J., Bar-Ilan, A., Dlugokencky, E. J., Patrick, L., Moore, C. T., Ryerson, T. B., Siso, C., Kolodzey, W., Lang, P. M., Conway, T., Novelli, P., Masarie, K., Hall, B., Guenther, D., Kitzis,
D., Miller, J., Welsh, D., Wolfe, D., Neff, W., and Tans, P.: Hydrocarbon emissions characterization in the Colorado Front Range: A pilot study, J. Geophys. Res.-Atmos., 117, D04304, doi:10.1029/2011JD016360, 2012b.

Pétron, G., Frost, G. J., Trainer, M. K., Miller, B. R., Dlugokencky, E. J., and Tans, P.: Reply to comment on "Hydrocarbon emissions characterization in the Colorado Front Range: A pilot study" by Levi, M. A., J. Geophys. Res.-Atmos., 118, 236-242, doi:10.1029/2012JD018487, 2013.

Rella, C., Crosson, E., Thoma, E., Hater, G., Merrill, R., Tan, S., and Green, R.: An Acetylene Tracer-Based Approach to Quantifying Methane Emissions from Distributed Sources Using Wavelength-Scanned Cavity Ring-Down Spectroscopy, American Geological Union Fall Meeting, San Francisco, California, USA, 2009.

Rochelle, G. T.: Amine Scrubbing for CO2 Capture, Science, 325, 1652-1654, 2009.

Shorter, J. H., McManus, J. B., and Kolb, C. E.: Collection of Leakage Statistics in the Natural Gas System by Tracer Methods, Environ. Sci. Technol., 31, 2012-2019, 1997.

Subramanian, R., Williams, L., Vaughn, T. L., Zimmerle, D., Roscioli, J. R., Herndon, S. C., Yacovitch, T. I., Floerchinger, C., Tkacik, D. S., Mitchell, A. L., Sullivan, M., and Robinson, A. L.: Methane Emissions from Natural Gas Compressor Stations in the Transmission and Storage Sector: Measurements and Comparisons with the EPA Greenhouse Gas Reporting Program Protocol, Environ. Sci. Technol., 49, 3252-3261, 2014.

Torres, V., Herndon, S. C., Kodesh, Z., and Allen, D. T.: Industrial Flare Performance at Low Flow Conditions. 1. Study Overview, Ind. Eng. Chem. Res., 51, 12559-12568, 2012.

Whiticar, M. J.: Correlation of Natural Gases with Their Sources, in: M 60: The Petroleum System-From Source to Trap, edited by: Magoon, L. B. and Dow, W. G., 261-283, 1994.

Wofsy, S. C., McKain, K., Chen, J., Levi, P., Gottlieb, E., Hutyra, L., Raciti, S. M., Phillips, N. G., Callahan, W., Decola, P., Jones, T., Hegarty, J. D., Nehrkorn, T., Mountain, M., Eluszkiewicz, J., Henderson, J., Budney, J., and Sweeney, C.: Measurements and modeling of $\mathrm{CH}_{4}$ and $\mathrm{CO}_{2}$ in the Boston Metro area and Northeastern Megalopolis, American Geophysical Union Fall Meeting, San Francisco, California, USA, 2013.

Yacovitch, T. I., Herndon, S. C., Roscioli, J. R., Floerchinger, C., McGovern, R. M., Agnese, M., Petron, G., Kofler, J., Sweeney, C., Karion, A., Conley, S. A., Kort, E. A., Nähle, L., Fischer, M., Hildebrandt, L., Koeth, J., McManus, B. J., Nelson, D. D., Zahniser, M., and Kolb, C. E.: Demonstration of an Ethane Spectrometer for Methane Source Identification, Environ. Sci. Technol., 48, 8028-8034, 2014.

Zavala-Araiza, D., Sullivan, D. W., and Allen, D. T.: Atmospheric Hydrocarbon Emissions and Concentrations in the Barnett Shale Natural Gas Production Region, Environ. Sci. Technol., 48, 5314-5321, 2014.

Zimmerle, D., Williams, L., Vaughn, T., Subramanian, R., Duggan, J., Willson, B., Opsomer, J., and Robinson, A.: Estimate of methane emissions from the natural gas transmission and storage system in the United States, in preparation, 2014. 